\title{
Guns And Roses: Flower Exports AND Electoral Violence in Kenya
}

\author{
Christopher Ksoll * $\quad$ Rocco Macchiavello $^{\dagger} \quad$ Ameet Morjaria ${ }^{\ddagger}$ \\ February $2021^{\S}$
}

\begin{abstract}
Violent conflicts, particularly at election times in Africa, are a common cause of instability and economic disruption. This paper studies how firms react to electoral violence using the case of Kenyan flower exporters during the 2008 post-election violence as an example. Consistent with our theoretical framework, the violence induced a large negative supply shock that reduced exports primarily through workers' absence and had heterogeneous effects: larger firms and those with direct contractual relationships in export markets suffered smaller production and losses of workers. On the demand side, international buyers were not able to shift sourcing to Kenyan exporters located in areas not directly affected by the violence nor to neighboring Ethiopian suppliers during the violence. Consistent with difficulties in insuring against supply-chain risk disruptions caused by electoral violence, firms in direct contractual relationships ramp up shipments just before the subsequent 2013 presidential election to mitigate risk.
\end{abstract}

\footnotetext{
*University of Greenwich and Mathematica; email: c.j.ksoll@gre.ac.uk

${ }^{\dagger}$ London School of Economics \& Political Science; email: r.macchiavello@lse.ac.uk

${ }_{\ddagger}^{\ddagger}$ Kellogg School of Management, Northwestern University; email: a.morjaria@kellogg.northwestern.edu

${ }^{\S}$ We thank Oriana Bandiera, Tim Besley, Chris Blattman, Robin Burgess, Stefan Dercon, Oeindrila Dube, Marcel Fafchamps, Maitreesh Ghatak, Asim Khwaja, Eliana LaFerrara, Adrienne LeBas, Guy Michaels, Torsten Persson, Fabian Waldinger, Chris Woodruff and seminar and conference participants at CalTech, CSAE Oxford, GWU Africa Political Economy 2016, Kellogg MEDS, LSE, Manchester, Mannheim, NEUDC Tufts, NOVAfrica Conference 2016, Oxford, Political Economy Chicago Area 2016, IEA 2017 Mexico, ASSA Chicago 2017, John Hopkins Carey, and Simon Fraser for helpful comments and suggestions. We gratefully acknowledge funding from iiG as part of the UK Department for International Development (DFID), George Webb Medley/Oxford Economic Papers fund and Dean's Research Award at Kellogg School of Management. Morjaria thanks LSE-STICERD and NSF-IGC-AERC for a travel award to Kenya and Ethiopia and EDRI for their hospitality. For excellent research assistance we are thankful to Ethan Nourbash, Ritwika Sen, Philip Spencer, Monica Toledo, and Timea Viragh. The views expressed are those of the authors alone and do not necessarily reflect those of DFID or any other acknowledged organization.
} 


\section{Introduction}

In many countries, political instability is a potentially major hindrance to firm performance. In the African context, violent conflicts, particularly at election times, are a common cause of instability and disruption (see, Bates, 2001, 2008). During the period from 1990 to 2018, $23 \%$ of the 348 elections which took place in Sub-Saharan Africa witnessed post-electoral violence (see Straus and Taylor, 2009, and Figure [1] for an update). ${ }^{1}$

An expanding body of evidence from cross-country studies (see, e.g., Alesina et al., 1996; Collier, 2007; Glick and Taylor, 2010) shows that violent conflicts have negative effects on growth, investment, and trade at the macro level. Micro-level evidence on the impact of violence on economic activity through firms' operations - necessary to understand the underlying mechanisms and formulate appropriate policies - remains limited. There are two major empirical challenges to providing micro-level evidence: (i) gathering detailed information on the operations of firms before, during, and after the violent conflict, and (ii) constructing a valid counterfactual - assessing what would have happened to the firms in the absence of the violence.

This paper investigates the mechanisms and costs of disruptions induced by the postelectoral violence in 2008 on the Kenyan floriculture industry. Export development is important to promote growth and poverty reduction in low income countries (see, e.g., Rodrik, 2005). The Kenyan floriculture industry provides an important example: one of the largest earners of foreign currency, the industry is also a major employer of lower educated women in rural areas. Besides its intrinsic relevance, the setting allows us to overcome the empirical challenges identified above. Kenyan flowers are produced almost exclusively for the export market. Since flowers are perishable, daily data on exports, available from trade transaction records at the firm level before, during, and after the violence, match day-by-day production activity on the farms. Moreover, flowers are grown and exported by vertically integrated firms and, therefore, the export data can also be matched with the exact location where flowers are produced $:^{2}$ The ethnic violence that followed the elections in Kenya at the end

${ }_{1}^{1}$ Straus and Taylor (2009) list cases with 20 or more deaths during elections. For comparison, Blattman and Miguel (2010) define civil wars as internal conflicts that count more than 1,000 battle deaths in a single year and civil conflicts as those that count at least 25 deaths per annum. The International Foundation for Electoral Systems (IFES) defines "election violence [a]s any harm or threat to any person or property involved in the election process, or to the election process itself, during the election period" (see http://www.ifes.org). A review of available sources and news articles reveals that of the 14 presidential, parliamentary, or legislative elections held in 2019, 8 saw violence before, during, or after the vote.

${ }^{2}$ Other perishable agricultural products, instead, are grown in rural areas and then processed and exported by firms located in the larger cities of Nairobi and Mombasa. This precludes matching production with 
of 2007 did not equally affect all regions of the country where flower firms are located. The detailed information on the time and location of production, therefore, can be combined with spatial and temporal variation in the incidence of the violence to construct several appropriate counterfactuals to assess the causal impact of the violence on production. The data, in particular, allow us to estimate firm-specific reduced form effects of the violence on production controlling for both seasonality and growth effects.

We complement these data with additional sources of information. We designed and conducted a survey of flower firms in Kenya shortly after the end of the violence. The survey collected information on how firms were affected by and reacted to the violence. The survey is combined with the administrative data to shed light on the mechanisms through which the violence affected the firms 3

The main finding is that the electoral violence induced a large, negative, supply shock in the industry. The results show that, after controlling for firm-specific seasonality and growth patterns, weekly export volumes of firms in the affected regions dropped, on average, by $56 \%$ relative to what would have happened had the violence not occurred. Guided by the predictions of the model, we investigate the mechanisms through which the violence affected the firms and show two sets of results. First, the evidence shows that workers' absence, which across firms averaged $50 \%$ of the labor force at the peak of the violence, was an important channel through which the violence affected production. Second, we explore sources of heterogeneity in both firms' exposure and response to the violence. We find that firms with stable contractual relationships in export markets registered smaller proportional losses in production and reported proportionally fewer workers absent during the time of the violence. Rather than being less exposed to the violence, we argue that these exporters had stronger incentives to maintain production to preserve valuable reputation in export markets and, accordingly, exerted more effort to retain workers. These results hold even after controlling for characteristics of the labor force (gender, ethnicity), working arrangements (housing programs on the farm, farm certifications) and ownership (foreign, politically connected). After accounting for these characteristics, we find no evidence that foreign-owned firms, firms more closely connected to politicians, or certified firms suffered differential reductions in exports and worker absence.

location. For other sectors - most manufacturing - that are not primarily involved in exports, accurate high-frequency data on production or sales do not exist.

${ }^{3}$ We also gathered additional administrative data, including transaction-level customs records from neighboring Ethiopia to understand the extent to which international buyers sourcing in Kenya were able to compensate the shortfall, as well as several other sources. 
Given the large negative supply shock, it is important to understand how the demand side of the market reacted to it. We document that, at the time of the violence, international buyers sourcing through direct relationships were not able to shift sourcing of flowers to Kenyan suppliers in unaffected locations nor to suppliers in neighboring Ethiopia. Buyers' difficulties in finding alternative sources of supply are consistent with exporters' efforts to maintain deliveries. They also suggest that supply-chain risks induced by electoral violence are hard to insure against. Consistent with this hypothesis, we find that exporters and buyers in direct contractual relationships mitigated the risk of supply-chain disruptions ahead of the subsequent 2013 presidential election by ramping up shipments just before the election.

This work contributes firm-level evidence on the impact of conflict on trade and firms, on the mechanisms that underpin its impact, and on the emerging literature on supply-chain disruptions. The literature on the impact of conflict on trade has largely studied disruptions at a more aggregate level. For instance, Glick and Taylor (2010) show that wars affect not only the parties directly affected, but also trade with third parties, while Nitsch and Schumacher (2004) show that terrorism within a country affects trade with other countries $4^{4}$ Our paper documents the effect of conflict on directly affected parties and the underlying mechanisms that contributed to the resulting decline in exports.5 Furthermore, our work suggests that the business arrangements developed by firms to participate in international value chains are important in determining the impact of conflict on trade.

A second strand of the literature assesses the effect of trade on conflict. Dube and Vargas (2013) study the effects of export trade on the incidence of conflict in Colombia, and find that an increase in the international price of a labor-intensive export commodity reduces violence, while an increase in the international price of a capital-intensive export goods increases violence. Amodio et al. (2017) posit that the imposition of trade restrictions contributes to conflict by inducing a deterioration in manufacturing and local labor market outcomes. This paper provides suggestive evidence that, at the time of the violence, stable contractual relationships in export markets might have provided incentives to limit the impact of the violence.

We also add to the literature that uses micro-level evidence to study the effects of conflict on firm performance. Our empirical setting and approach relate to those of Abadie and Gardeazabal (2003) and Guidolin and La Ferrara (2007), who also focus on natural

\footnotetext{
${ }^{4}$ Collier and Hoeffler (1998), Besley and Persson (2008), and Martin et al. (2008) provide further examples of macro-level evidence on the relationship between trade and civil conflict.

${ }^{5}$ Recent work by Korovkin and Makarin (2019) estimates the effects of conflict on trade in non-conflict areas using transaction-level customs records between Russia and Ukraine.
} 
experiments arising from particular instances of conflict. Abadie and Gardeazabal (2003) study the impact of the Basque terrorist conflict on growth in the Basque region by comparing the growth outcomes of the Basque country to that of a counterfactual region. They then look at stock market returns of firms who operated in the Basque region when the terrorist organization announced a truce and find that the announcement of the cease-fire led to excess returns for firms operating in the area. Guidolin and La Ferrara (2007) conduct an event study of the sudden end of the civil conflict in Angola, which was marked by the death of the rebel movement leader in 2002. They find that the stock market perceived this event as "bad news" for the diamond companies holding concessions there. The main difference between these papers and ours is that we provide evidence on the effect of conflict on firms using firm-level export and survey records, rather than stock-market data. In contrast to stock market reactions, our data allow us to unpack the various channels through which the violence has affected firms' operations.6

The more recent literature augments our understanding of conflict and firm performance by investigating the underlying mechanisms. Conflict may affect firm performance through supply-side shocks such as distortions in markets for material and labor inputs (Amodio and Di Maio, 2017; Klapper et al., 2013; Collier and Duponchel, 2013), unreliable transport, or the fear of theft; demand shocks from negative income effects (Montoya, 2016, Rozo, 2018); or effects at the extensive margin which influence firms' entry, exit, and location choices (Blumenstock et al., 2018). Hjort (2014) also studies the Kenyan flower industry in the aftermath of the 2008 presidential elections, although he focuses on the operations of an individual flower farm (whereas we provide sector-wide firm-level evidence), and the effects of conflict on firm performance through the channel of ethnic divisions within a firm. Our paper contributes to the literature by characterizing both the supply-side and demand-side responses to a short-lived, but intense, episode of violence. $7^{7}$

Finally, the paper contributes to the emerging literature on supply-chain disruptions. For example, Carvalho et al. (2021) exploit the Great East Japan Earthquake of 2011 to quantify the role of input-output linkages as a mechanism for the propagation of shocks.

\footnotetext{
${ }^{6}$ There is also a fairly mature strand of literature on the microeconomics of violence and civil conflict focusing on the impact of conflict on investment in human capital and children, e.g., Akresh and De Walque (2008), Blattman and Annan (2010), León (2010) and Miguel and Roland (2011). This literature is surveyed in Blattman and Miguel (2010).

"Dercon and Gutiérrez-Romero (2012) and Dupas and Robinson (2012) provide survey-based evidence of the violence that followed the Kenyan presidential elections. Dupas and Robinson (2012) document large effects of the violence on income, consumption and expenditures on a sample of sex workers and shopkeepers in Western Kenya.
} 
Barrot and Sauvagnat (2016) also study the extent to which firm-level shocks induced by natural disasters propagate in production networks and find particularly large effects for inputs that require specific investments. Blouin and Macchiavello (2019) show that the risk of delivery failures increases at times of sudden price spikes due to moral hazard. Finally, Macchiavello and Morjaria (2015) study relational contracts between exporters and international buyers in the Kenyan floriculture industry. They exploit the same episode of electoral violence to distinguish across competing models of relational contracting. The two papers are notably different. Unlike this paper, they focus on within-exporters differences in behaviour across relationships and treat the electoral violence as a reduced form of shock. In contrast, this paper documents the mechanisms through which the violence was a supply shock and explores across-firms heterogeneity in the incidence of, and response to, the violence. Using novel data, this paper also discusses the extent to which international buyers responded by shifting sourcing across regions in Kenya and, across the border to Ethiopia, and by adjusting ahead of the subsequent presidential election.

The remainder of the paper is organized as follows. Section 2 provides some background information on the Kenyan flower industry and the post-electoral violence and describes the data. Section 3 presents the theoretical framework. Section 4 presents the estimation strategy and empirical results. Section 5 discusses policy implications of our findings and offers concluding remarks.

\section{Background and Data}

\subsection{Kenyan Flower Industry}

In the the last two decades Kenya has become one of the leading exporters of flowers in the world. Between 2005 and 2015 Kenya's share of the global floriculture increased from $5 \%$ to $11 \%$ with the country overtaking traditional producers such as Israel and Ecuador 8 Exports of cut flowers are among the largest sources of foreign currency for Kenya alongside tourism and diaspora remittances 9 The Kenyan flower industry counts around 100 established exporters located in various clusters in the country.

\footnotetext{
${ }^{8}$ World Floriculture Map 2016, https://research.rabobank.com/far/en/sectors/ regional-food-agri/world_floriculture_map_2015.html, accessed December 2019.

${ }^{9}$ See, for instance, http://atlas.cid.harvard.edu/countries/116/export-basket, accessed December 2019.
} 
Since flowers are a fragile and highly perishable commodity, growing flowers for exports is a complex business. In order to ensure the supply of high-quality flowers to distant markets, coordination along the supply chain is crucial. Flowers are handpicked in the field, kept in cool storage rooms at constant temperature for grading, then packed, transported to the airport in refrigerated trucks, inspected, and sent to overseas markets. The industry is labor intensive and employs mostly low-educated women in rural areas. The inherent perishable nature of the flowers implies that post-harvest care is a key determinant of quality. Workers, therefore, receive significant training in harvesting, handling, grading, and packing, acquiring skills that are difficult to replace in the short run. Because of both demand (e.g., particular dates such as Valentines' Day and Mother's Day) and supply factors (it is costly to produce flowers in Europe during winter), floriculture is a business characterized by significant seasonality. Flowers are exported from Kenya either through the Dutch auctions located in the Netherlands, or through direct sales to wholesalers and/or specialist importers. In the first case, the firm has no control over the price and has no contractual obligations for delivery. In the latter, instead, the relationship between the exporter and the foreign buyer is governed through a (non-written) relational contract.

\subsection{Electoral Violence}

Kenya's fourth multiparty general elections were held on the December 27, 2007 and involved two main candidates: the incumbent Mwai Kibaki was running for re-election, a ethnic Kikuyu hailing from the Central province representing the Party of National Unity (PNU). Raila Odinga, a ethnic Luo from the Nyanza province, represented the main opposition party, the Orange Democratic Movement (ODM). The support bases for the two opposing coalitions were clearly marked along ethnic lines (see Kimenyi and Shughart, 2010; Bratton and Kimenyi, 2008; Gibson and Long, 2009).

Polls leading up to the elections showed that the race would be close. Little violence occurred on election day, and observers considered the voting process orderly. Exit polls gave a comfortable lead to the challenger, Odinga, by as much as $50 \%$ against $40 \%$ for Kibaki. The challenger led on the first day of counting (December 28) leading to an initial victory declaration by ODM (December 29). However, also on the $29^{\text {th }}$, the head of the Electoral Commission of Kenya declared Kibaki the winner, by a margin of $2 \%$. The hasty inauguration of Kibaki on the afternoon of the December 30, resulted in Odinga accusing 
the government of fraud 10 Within minutes of the announcements of the election results, a political and humanitarian crisis erupted nationwide. Targeted ethnic violence broke out in various parts of the country, especially in Nyanza, Mombasa, Nairobi and parts of the Rift Valley, where ODM supporters targeted Kikuyus who were living outside their traditional settlement areas of the Central province. This first outburst of violence, which lasted for a few days, was followed by a second outbreak of violence between January 25-30, 2008. This second phase of violence happened mainly in the areas of Nakuru, Naivasha, and Limuru as a revenge attack on members of ethnic groups perceived to be ODM supporters ${ }^{11}$ Sporadic violence and chaos continued until a power-sharing agreement was reached on the February 29, 2008 (a calendar of events is provided in Appendix Figure B1]). By the end of the violence some 1,200 people had died in the clashes and at least 500,000 were displaced and living in internally displaced camps (Gibson and Long, 2009). The economic effects of the crisis were extensively covered in the international media. 12

\subsection{Data}

Firm-Level Data. Daily data on exports of flowers are available from trade transaction records for the period from September 2004 to June 2013. We restrict our sample to established exporters that export throughout the majority of the floriculture season. For most of the analysis, we exclude traders as they account for a relatively tiny share of exports and we lack information on the location of farms where they source flowers. This leaves us with 118 flower-producing firms. The firms in our sample cover more than 90 percent of all exports of flowers from Kenya. We complement the Kenya trade transaction records with records from neighbouring Ethiopia for the 2007-2010 period.

To complement the trade transaction records, we designed and conducted a survey of the industry. The survey was conducted by two of the authors in the summer following the violence through face-to-face interviews with the most senior person at the firm, which on most occasions was the owner. A sample of 75 firms, about three-fifths of established exporters, located in all the producing regions of the country, was surveyed (additional details

\footnotetext{
${ }^{10}$ According to domestic and international observers the vote counting was flawed with severe discrepancies between the parliamentary and presidential votes (see, e.g., http://www.iri.org/africa/kenya or http://www.senate.gov/ foreign/testimony/2008/MozerskyTestimony080207a.pdf)

${ }^{11}$ See, Kenya National Commission on Human Rights (2008), Independent Review Commission (2008) and Catholic Justice and Peace Commission (2008).

${ }^{12}$ See, e.g., The International Herald Tribune (29/01/2008), Reuters (30/01/2008), China Daily (13/02/2008), MSNBC (12/02/2008), The Economist (07/02/2008, 04/09/2008), The Business Daily (21/08/2008) and The East African Standard (14/02/2008).
} 
on the data collection can be found in Appendix D. Further administrative information on location and ownership characteristics was collected for the entire sample of firms (see Table 1]) 13

Location and Days of Violence. We classify whether firms are located in areas that were affected by violence or not 14 The primary source of information used to classify whether a location suffered from violence or not is the Kenya Red Cross Society's Information Bulletin on the Electoral Violence (Kenya Red Cross Society, 2008). These bulletins contain daily information on which areas suffered violence and what form the violence took (deaths, riots, burning of property, etc.). This information is supplemented by various sources, as further detailed in Appendix D. The first spike of violence took place from the December 29, 2007 to January 4, 2008 while the second spike took place from January 25-30, 2008.15

\section{Theoretical Framework}

This section presents a theoretical framework to understand how firms were affected by, and reacted to, the violence. The model focuses on the aspects that are most salient to understand the particular episode we study and is not meant to portray a comprehensive treatment of how firms might be affected by violence. In particular, we take a short-run perspective in which a firm's capital and other input decisions are fixed, we assume an exogenous price for output not affected by the violence, and abstract from how the violence might increase uncertainty. The model derives predictions which are tested in the next section.

\subsection{Setup}

Consider a firm with the production function

$$
q=\theta N^{\beta}\left[\int_{i \in N} l_{i}^{\frac{1}{\alpha}} d i\right]^{\alpha},
$$

\footnotetext{
${ }^{13} \mathrm{We}$ also gathered qualitative information on firms' behavior in preparation for the 2013 Kenyan presidential election through phone interviews with a few firms.

${ }^{14}$ In Appendix Table $[\mathrm{C} 1$ lists the flower-growing clusters (according to industry reports) in which firms are located. Figure 2 shows the nearest towns where these firms are located within Kenya.

${ }^{15}$ Appendix Figure B1 outlines the calendar of events which we use as a basis for defining the days of violence occurrence.
} 
where, with some abuse of notation, $N$ is the set as well as the measure of hired workers, i.e., $i \in N ; l_{i}$ is the hours worked by each worker $i$; and $\theta$ is a firm-specific parameter. The production function allows for productivity gains due to specialization through the term $N^{\beta}$, with $\beta \geq 0$. Note that we abstract from other inputs, such as materials and capital, since those are fixed over the short-run period during which the violence occurred.

Worker $i^{\prime} s$ utility function is given by $u(\cdot)=y_{i}-\frac{l_{i}^{1+\gamma}}{1+\gamma}$, where $y_{i}$ denotes her income and $\gamma>0$. Each worker has a reservation utility $\bar{u}$. The firm sells flowers in a foreign market taking the world price $p$ as given.

In practice, firms in the flower industry hire and train workers at the beginning of the season - September to October. Since we are interested in studying a short episode of ethnic violence which happened in the middle of the season, we take the pool of hired and trained workers $N$ as given and focus for now on the firm's choice of hours worked $l_{i}$, which can be adjusted throughout the season 16 When studying the firm's reaction to the ethnic violence, we will allow the firm to partially adjust the labor force as well.

The profits of the firm can be written as

$$
\Pi(\theta)=p \theta N^{\beta}\left[\int_{i \in N} l_{i}^{\frac{1}{\alpha}} d i\right]^{\alpha}-\int_{i \in N} w_{i} l_{i} d i .
$$

The firm offers a contract to each worker which specifies the amount of hours to be worked, $l_{i}$, and a wage per hour, $w_{i}$. We assume a large pool of identical workers from which the firm can hire and, therefore, each contract offered by the firm satisfies the worker's participation constraint with equality. Since a worker's income is equal to $y_{i}=w_{i} l_{i}$, the binding participation constraint implies $w_{i} l_{i}=\frac{l_{i}^{1+\gamma}}{1+\gamma}+\bar{u}$. It is easy to check that the profit function of the firm is concave and symmetric in $l_{i}$ and, therefore, the optimal solution entails $l_{i}=l_{j}, \forall i, j \in N$. For convenience, we set $\bar{u}=0$ and denote $\eta=\beta+\alpha$, with $\eta \in\left(\frac{1}{1+\gamma}, 1\right) \cdot 17$ The profit function can then be rewritten as

$$
\Pi(\theta)=p \theta N^{\eta} l-N \frac{l^{1+\gamma}}{1+\gamma} .
$$

The firm chooses the optimal $l$ taking as given $N, \theta$, and $p$. The following statement charac-

\footnotetext{
${ }^{16}$ It is straightforward to relax this assumption, and show that the optimal $N$ is an increasing function of $\theta$. Considering this would not alter the predictions obtained below.

${ }^{17}$ The production function thus allows for imperfect substitution across workers who might be involved in different tasks $(\alpha<1)$ and for gains from specialization $(\beta \geq 0)$. Provided overall returns to scale guarantee the second order conditions are satisfied, the model can accommodate the special case with perfect substitution, and no gains from specialization.
} 
terizes a firm production, wages and profits in normal times.

Observation: Denote by $R^{*}=\left(p \theta N^{\eta-1}\right)^{1+\frac{1}{\gamma}}$ the revenues per worker in normal times. Then, total production is $q^{*}=\frac{R^{*}}{p} N$, profits are $\Pi^{*}=\frac{\gamma}{\gamma+1} R^{*} N$, and hours worked are $l^{*}=\left(R^{*}\right)^{\frac{1}{1+\gamma}}$.

\subsection{Ethnic Violence: Workers' Absence}

The main channels through which firms were differentially affected across regions by the violence have been (i) the absence of workers, and (ii) transportation problems. ${ }^{18}$ In our context, it might take up to 400 workers to pluck, cut, arrange, and pack an amount of flowers that fills up one single truck. Once the truck is ready to take the flowers to the airport, it only takes one driver and, during the violence, a security guard to operate it. The interviews in the field reveal that firms paid fixed costs (e.g., hired security) to ensure they could safely deliver flowers to the airport. Generally speaking, however, respondents report that increases in transport costs were small and not a major impediment to exporting. ${ }^{19}$ For these reasons, this section focuses on the worker absence channel and relegates to Appendix A an extension of the model that deals with transportation problems.

In line with interviews conducted in the field, we assume that the shock was completely unanticipated by firms. Since violence was not targeted towards firms but rather individuals in the general population, we model the violence as an exogenous shock to the reservation utility of workers. In particular, assume that worker $i$ faces a cost $c_{i} \geq 0$ of coming to work during the period of violence. The costs $c_{i}$ are independently drawn from a distribution with continuous and differentiable cumulative function $F(c, \mathbf{C})$, where $\mathbf{C}$ parameterizes the intensity of the violence at the firm's location. The cost $c_{i}$ captures, in a parsimonious way, various reasons why many workers found it harder to go to work - e.g., (i) psychological and expected physical costs due to the fear of violence during the commuting and/or on the farm, (ii) the opportunity cost of leaving family and properties unguarded

\footnotetext{
${ }^{18}$ The sudden electoral violence would also lead to more uncertainty in the business climate. Since our survey was retrospective we lack detailed information on the firms' perceptions of risk during the events and we thus abstract from this channel. In the empirical section, however, we also explore firms' behavior ahead of the subsequent presidential election in 2013, a time in which the risk of supply-chain disruptions increased and firms adopted precautionary measures in response.

${ }^{19}$ Firms also coordinated convoys to increase security and, indeed, ensuring that trucks could go to the airport was one of the government priorities during the violence. Media reported that the police dislodged roadblocks along the main routes from the flower farms to the airport.
} 
while at work, and (iii) the opportunity cost of fleeing to the region of origin for security reasons or to be closer to family members that were experiencing violence.

Given $\operatorname{cost} c_{i}$, a worker offered a wage $w_{i}^{v}$ to work for $l_{i}^{v}$ hours comes to work if

$$
w_{i}^{v} l_{i}^{v}-\frac{\left(l_{i}^{v}\right)^{1+\gamma}}{1+\gamma} \geq c_{i}
$$

where the superscript $v$ makes explicit that the firm re-optimizes the wage policy at the time of the violence and might choose to compensate workers for the costs of coming to work.

In adjusting the labor force to the new circumstances, the firm keeps the "cheapest" workers - i.e., an interval of workers that have low realizations of the shock $c_{i}$. Furthermore, due to the symmetry of the production function, it is optimal for all workers kept at the farm to work $l^{v}$ hours. The optimal policy for the firm, therefore, consists of choosing (i) the threshold $c^{v}$ such that workers with $c_{i} \leq c^{v}$ come to the farm, and (ii) the hours worked by each worker, $l^{v}$. For simplicity, we maintain the assumption that the firm can offer different wage contracts $w_{i}^{v}$ to each worker $i \cdot{ }^{20}$ The problem of the firm can then be rewritten as

$$
\max _{c, l} \Pi^{v}=p \theta(N \times F(c, \mathbf{C}))^{\eta} l-(N \times F(c, \mathbf{C})) \frac{l^{1+\gamma}}{1+\gamma}-N \int_{0}^{c} s d F(s, \mathbf{C})-K .
$$

Assuming an interior solution in which the share of workers that come to work during the violence is $\sigma_{v}=F\left(c^{v}, \mathbf{C}\right)<1$, the first order conditions imply

$$
l^{v}=l^{*} \sigma_{v}^{\frac{\eta-1}{\gamma}}>l^{*} \text { and } c^{v}=\eta\left(R^{*}\right)^{\frac{\gamma}{1+\gamma}}\left(\sigma_{v}\right)^{\eta-1} l^{v}-\frac{\left(l^{v}\right)^{1+\gamma}}{1+\gamma} .
$$

The two first order conditions deliver several implications ${ }^{21}$ First, by increasing the cost of coming to work for the worker, the impact of violence on production is negative. This is our first prediction. The reduced form effect of the violence on production, $\Delta^{v}=\ln \left(\frac{q^{v}}{q^{*}}\right)$, is given by

\footnotetext{
${ }^{20}$ None of the qualitative results are affected by allowing the firm to offer worker specific wages $w_{i}^{v}$. In practice, firms arranged transportation and accommodation for the workers that had problems coming to the farm. Some part of the costs, therefore, have been worker specific. If, however, firms had to pay a common wage, infra-marginal workers would earn rents. This does not mean they benefited from the violence since, presumably, overall utility would be lower through other channels. As we have no data on individual workers, we refrain from exploring how the violence affected them.

${ }^{21}$ We assume that the second order condition is satisfied - i.e., $\frac{\partial^{2} \Pi^{v}}{\partial l^{2}}<0, \frac{\partial^{2} \Pi^{v}}{\partial c^{2}}<0$ and $\frac{\partial^{2} \Pi^{v}}{\partial l^{2}} \cdot \frac{\partial^{2} \Pi^{v}}{\partial c^{2}}-$ $\left(\frac{\partial^{2} \Pi^{v}}{\partial l \partial c}\right)^{2}>0$. It is straightforward to check that $\frac{\partial^{2} \Pi^{v}}{\partial l^{2}}<0$ holds. The remaining conditions hold, e.g., when $F(\cdot)$ is either uniform or exponential for reasonable parameterizations of the production function.
} 


$$
\Delta^{v}=\underbrace{\eta \ln \sigma_{v}}_{\text {retained workers }}+\underbrace{\ln \left(\frac{l^{v}}{l^{*}}\right)}_{\text {extra hours worked }}=\frac{\eta(1+\gamma)-1}{\gamma} \ln \left(\sigma_{v}\right) .
$$

The effect of the violence on production can be decomposed into two effects: the negative effect coming from a reduction in the number of workers coming to work, $\eta \ln \sigma_{v}<0$, is partially offset by a positive effect on the hours worked, $\ln \left(\frac{l^{v}}{l^{*}}\right)>0 .{ }^{22}$

Second, the model provides guidance on how to quantify the impact of the violence on firm profits. Defining $\mu=\frac{\eta(1+\gamma)-1}{1+\gamma}$ and substituting $\Delta^{v}$ and $l^{v}$ in the first order condition for $c^{v}$, we obtain, after some manipulation,

$$
c^{v}=\mu R^{*} \times \sigma_{v}^{-\frac{(1-\eta)(1+\gamma)}{\gamma}}=\mu R^{*} \times e^{-\frac{1-\eta}{\mu} \Delta^{v}} .
$$

The estimated effect of the violence on production, $\Delta^{v}$, therefore, can be combined with information on revenues per worker during normal times, $R^{*}$, to recover a bound to the extra costs incurred by the firm at the time of the violence 23

\subsection{Heterogeneity in the Reduced Form Effects}

This section discusses two comparative statics suggesting heterogeneous reduced form effects of the violence on production, $\Delta^{v}$, depending on firm's size and marketing channel.

Size Effects: Consider first a proxy for the size of the firm, given by the quantity produced in normal time, $q^{*}$. The equation (8) can be rewritten as

$$
\left(c^{v} \times \sigma_{v}, \mathbf{C}\right)^{\frac{(1-\eta)(1+\gamma)}{\gamma}}=\frac{\mu p q^{*}}{N} .
$$

Straightforward implicit differentiation of equation $(9)$ gives $\frac{\partial c^{v}}{\partial q^{*}}>0$ and, by equation (7), $\frac{\partial \Delta^{v}}{\partial q^{*}}>0{ }^{24}$ This means that the effect of the violence on production and worker loss is greater

\footnotetext{
${ }^{22}$ Since the share of workers coming to work during the violence is endogenously chosen by the firm, a reduced form regression of $\Delta^{v} \ln \sigma_{v}$ gives a biased estimate of $\eta$, i.e., $\frac{\eta(1+\gamma)-1}{\gamma}<\eta$.

${ }^{23}$ In order to recover $c^{v}$, knowledge of the parameters $\gamma$ and $\eta$ is required. Note, however, that the share of the wage bill in revenues, which can be obtained from the survey, is equal to $\frac{1}{1+\gamma}$, and that, for a given $\gamma$, an estimate of $\eta$ can be recovered from the relationship between the effects of the violence on production, $\Delta^{v}$, and the share of workers coming at the firm, $\sigma_{v}$, as suggested by equation (7).

${ }^{24}$ While implicit differentiation of equation $\sqrt{9}$ implies $\frac{\partial \Delta^{v}}{\partial N}<0$, if $N$ was endogenously chosen by the firm, the model would predict a positive correlation between $\Delta^{v}$ and $N$. Since export data are available for
} 
for smaller firms.

Marketing Channels: Some firms in the industry export flowers through direct relationships with foreign buyers. In such case, the firm receives a unit price $p_{d}$ which is agreed upon at the beginning of the season for delivering a prespecified quantity $q^{*}$. In these relationships, firms might suffer a penalty for failing to deliver the agreed quantity. We are not interested in explicitly deriving the penalty schedule. We think of the penalty as arising from reputation losses, rather than stemming from an enforceable clause stipulated in a contract. Macchiavello and Morjaria (2015) document that these relationships are typically not governed by written contracts. In the unlikely event parties had stipulated a contract with enforceable penalties, the foreign buyers would likely have suspended any penalties for failing to deliver the contracted quantities during this period (e.g., most contracts allow for exceptions due to acts of God). Indeed, Macchiavello and Morjaria (2015) find evidence that exporters strategically responded to the violence to maintain a reputation for being a reliable supplier with their main customers.

For simplicity, we assume that if the firm delivers a quantity $q<q^{*}$ to the buyer, the firm incurs a reputation loss worth $\Omega\left(q^{*}-q\right)>0$. The reputation loss is zero otherwise. ${ }^{25}$ The firm can always sell flowers to the spot market at a price $p$. Therefore, a necessary condition on the shape of the penalty function $\Omega(\cdot)$ to induce the firm to ship flowers to the buyer is

$$
p_{d} \geq p-\frac{\partial \Omega}{\partial q}
$$

if $q<q^{*}{ }^{26}$ Inspection of equation $(9)$ when $p$ is replaced by $p_{d}-\frac{\partial \Omega}{\partial q}$ shows that, in responding to the violence, a firm engaged in a contract with a direct buyer has stronger incentives to retain workers and keep producing relative to a firm which takes prices as given on the spot market. The model thus suggests that, during the violence, firms that sell through direct relationships might end up being worse off than firms that sell at exogenous prices to the international market as they incur additional costs to avoid the penalty ${ }^{27}$

all firms in the sample while labor force is available only for surveyed firms, it is convenient to measure size in terms of export volumes and avoid the unnecessary complication of endogenizing $N$ in the model.

${ }^{25}$ One could imagine that the violence provides an opportunity for firms to prove their worth. What matters for incentives, however, is the slope, rather than the level, of the payoffs function.

${ }^{26}$ Note that $\frac{\partial \Omega}{\partial q}<0$ allows for $p_{d}<p$. If this condition was violated at $q^{*}$, the firm would prefer to reduce the shipment to the buyer and obtain higher prices on the spot market.

${ }^{27}$ These firms also suffer lower revenue losses, but in the absence of the penalty they would have (optimally) chosen a lower production. 


\subsection{Summary of Predictions}

The framework delivers a set of testable predictions on the short-run effects of the violence on the firms. To summarize, the model suggests:

1. Export volumes decrease due to the violence. In Appendix A we also show that (i) the likelihood of exporting on any given day also decreases because of the violence, but (ii) export volumes conditional on exporting might either increase or decrease as a consequence of the violence depending on the relative importance of the reduction in the number of workers coming to work versus transportation problems.

2. The reduced form effect of the violence on production is greater for smaller firms and firms selling mainly to the auctions.

3. The mechanism works through the reduction in the number of workers coming to work. Smaller firms and firms selling mainly to the auctions, therefore, lose a higher proportion of their workers. Furthermore, if the proportion of workers who do not show up for work is directly controlled for, those firms do not suffer larger reductions in exports.

\section{Evidence}

This section presents the empirical results. Section 4.1 discusses the identification strategy and presents the reduced form effects of the violence on production. Section 4.2 discusses a variety of robustness checks and other outcomes. Section 4.3 introduces information from the survey to disentangle the main channels through which the violence affected the industry and considers heterogeneous effects for the firms during the violence. Finally, Section 4.4 considers the extent to which international buyers could react to the violence by shifting sourcing elsewhere and how the supply chain responded to increased risk ahead of the subsequent presidential election in 2013.

\subsection{Reduced Form Estimate of the Effect of Violence on Exports}

In this section we quantify the effects of the violence on firms' exports. The location and timing of the violence was driven by the interaction between political events at the national 
and local level and regional ethnic composition (see Gibson and Long, 2009). Therefore, the occurrence of violence in any location was not related to the presence of flower firms. In fact, intense violence was registered in many locations outside of our sample - i.e., in places without flower firms (e.g., slum areas in Nairobi and other major towns). To assess the effect of the violence on the industry we condition on flower firms' locations and exploit the cross-sectional and temporal variation in the occurrence of violence between "violence" and "no-violence" regions ${ }^{28}$ In an extension we also use measures of conflict that allow for the intensity of conflict to vary, and this intensity to have affects at different radii from the epicenter of the violent events (see Table [4).

Table [1] reports summary statistics for the industry in the two regions. Panel A reports data from the administrative records, while panel B focuses on information obtained through the survey. Both panels show that firms in the regions affected by the violence are broadly similar to firms in regions not affected by the violence. It is important to stress that our identification strategy does not rely on the two groups of firms being similar along timeinvariant characteristics, since these are always controlled for by firm fixed effects. Finally, panel $\mathrm{C}$ shows that the sample of surveyed firms is representative of the entire industry. To focus on the effects of the violence, however, firms in the violence region were over-sampled in the survey.

Table [2] presents estimates of the short-run impact of the violence. In order to estimate the impact of the violence on production, it is necessary to control for both growth across years and the fact that exports within any year follow a seasonal pattern. Let $Y(i)_{T, W}^{L}$ be the exports of flowers by firm $i$ located in location $L$ in period $T$ in winter $W$. The indicator $L$ takes a value of $L=1$ if the firm is in a location that is affected by the violence after the election and $L=0$ otherwise. The indicator $T$ takes a value of $T=1$ during the weeks in January and early February during which violence occurred and $T=0$ during our control period, which are the 10 weeks before the end of December. Finally, the indicator $W$ takes value equal to $W=1$ in the winter during which the violence occurred - i.e., the winter of $2007 / 8$ and $W=0$ for the previous winter. With this notation, a firm was directly affected during a particular spike of violence if and only if $V=L \times T \times W=1$.

\footnotetext{
${ }^{28}$ In some locations flower farms are relatively large employers. To eliminate concerns that a firm's response and behavior at the time of the crisis affected the intensity and/or duration of violence in its location, we take an "intention-to-treat" approach in which we classify locations as having suffered violence or not during a prespecified time spell which is kept constant across locations involved during the same spike (see Appendix $D$ for details on the conflict data and Appendix Figure B1 for the specific timeline and exact dates of the violence).
} 
Panel A focuses on the first spike of violence, while panel B focuses on the second spike. The two panels, therefore, differ in their definition of the violence period $T=1$ (but not of the control period $T=0$ ). The two panels also differ in the division of firms across locations classified as being affected by the violence, i.e., L. In panel A there are 20 firms affected by the violence, while in panel B, 55 firms are located in regions affected by the second spike of violence. In both panels the sample includes 135 firms.

Under the assumption that the change in exports between $T=0$ and $T=1$ is constant across winters, it is possible to estimate the effects of the violence on production for each firm $i$ by looking at the following difference-in-difference:

$$
\widehat{\gamma}^{L}(i)=\underbrace{\left(Y_{T=1, W=1}^{L}-Y_{T=1, W=0}^{L}\right)}_{\Delta_{T=1}^{L}(i)}-\underbrace{\left(Y_{T=0, W=1}^{L}-Y_{T=0, W=0}^{L}\right)}_{\Delta_{T=0}^{L}(i)} .
$$

Intuitively, this means - for example - that the worldwide demand for flowers for the time of January and February relative to the 10 weeks leading up to Christmas did not change across the two seasons. The first difference, $\Delta_{T=1}^{L}(i)$, compares exports during the time of the violence with exports at the same time in the previous winter. This simple difference, however, confounds the effects of the violence with a firm's growth rate across the two winters, which is of particular importance in a fast-growing sector. The second difference, $\Delta_{T=0}^{L}(i)$, provides an estimate of the firm's growth rate comparing the non-violence periods - the 10 weeks before Christmas - in the two winters. Under the assumption that the growth rate between two successive winters is the same for the weeks before Christmas and in January/February, the difference-in-difference $\widehat{\gamma}^{L}(i)$ provides an estimate of the effects of the violence which controls for a firm's growth rate. Appendix Table [C2] uses data from the two seasons preceding the violence to provide support for this identifying assumption. The table shows that seasonality patterns are constant across seasons and similar across regions. ${ }^{29}$

The bottom rows in panel A and panel B of Table [2] report the average $\widehat{\gamma}(i)$ across firms for the two spikes of violence, with columns (A) and (B) presenting the results for the no-violence region and the violence regions, respectively. The results in panel A show that the violence had a dramatic impact on the 20 firms that were directly affected by the first spike of violence. Rows [3a] and [4] in column (B) show that estimated coefficients for the simple difference and the difference-in-difference estimates for the effects of the first

\footnotetext{
${ }^{29}$ Later, we provide further support to the identification strategy by reporting parallel trends across regions. For intuition, the identification strategy is also provided graphically in Appendix Figure B2.
} 
spike of violence are -1.83 and -1.48 (which translate roughly to a $56 \%$ drop in exports). Panel B shows that the larger group of 55 firms that were directly affected by the second spike of violence suffered a smaller reduction in exports, a difference that is not statistically significantly different from zero.

The difference between Rows [3a] and [4] in panel A highlights why accounting for seasonality is so important: the simple difference overestimates the effect of violence on firms affected by conflict (as estimated by the difference in difference in row [4]) by -0.34, as it does not take into account the lower demand for flowers in the first few weeks of the year relative to the period before the election. This is also a possible explanation for the statistically significant simple difference within the no-violence region of -0.53 (which is also about -0.34 smaller than the estimated effect of this period in the no-violence region) .

Panel B shows diverging experiences in the second spike of the violence. The differencein-difference point estimate in the violence region is negative, while it is positive in the towns not directly involved in the violence. Neither of the two coefficients is statistically significant at conventional levels. The positive point estimate for no-violence regions could arise if firms where trying to make up for losses during the first spike or if there were positive spillovers. Positive spillover could arise, e.g., if buyers who prior to the conflict sourced from violence areas might try to source from non-violence locations to satisfy their unmet demand and hence this could cause an increase in exports. Section 4.4 explores this scenario directly and finds no evidence in support of this channel.

Cross-Regional Comparison: Triple Differences. One limitation of the difference-indifference estimates is that they do not account for demand shocks that are specific to a date and winter. This would be the case, for example, if European demand were particularly high for roses for the 2007/2008 new year. A difference-in-differences approach would conflate such demand shocks with the supply shocks induced by the violence. Under the assumption that any change in the seasonality across winters is the same for the violence and no-violence areas (which also excludes cross-region spillovers), firms in regions not directly affected by the violence can also be used as a control group to estimate the direct effects of the violence

and to account for such demand shocks. Defining by $\bar{\Delta}^{L}=\frac{1}{N_{C}} \Sigma_{i \in C} \widehat{\gamma}^{L}(i)$ the average of the difference-in-difference estimates for each firm in location $L$, a triple difference estimate of the direct impact of the violence is given by

$$
\Delta=\bar{\Delta}^{L=1}-\bar{\Delta}^{L=0}
$$


The triple difference estimates are presented in column (C) of Row [4] in each of the two panels. For the first shock of violence, the triple difference is -1.30 , roughly in line with the difference-in-difference estimates. The triple difference estimate for the second spike of violence is roughly half in size, at -0.61 .

Conditional Regressions. Panel A in Table [3] estimates the impact of the violence on production using daily export data. The estimated regression is given by

$$
y_{i d}=\alpha_{i}+\mu^{m}+\eta^{d}+\lambda^{W}+\theta(\mathbf{W} \times \mathbf{T})+\gamma_{D D D}(\mathbf{W} \times \mathbf{T} \times \mathbf{L})_{i d}+\varepsilon_{i d}
$$

where $y_{i d}$ denotes exports of firm $i$ on a particular date (e.g., January 20, 2008). Location $L \in\{0,1\}$ and period $T \in\{0,1\}$ are defined as above while winter $W \in\{0,1\}$ is defined over all available years, i.e., with $W=0$ indicating the three winters pre-dating the violence and $W=1$ the winter of $2007 / 8$. Day of the week dummies (i.e., Monday, Tuesday...) are denoted by $m$. The specifications control for firm-specific effects $\alpha_{i}$; day of the year effect $\eta^{d}$; winter-specific effect $\lambda^{W}$ (where we allow a different $\lambda^{W}$ for each of the four winters); as well as day of the week effect $\mu^{m}$. Finally, $\varepsilon_{i d}$ is an error term 30

The indicator functions $\mathbf{W}, \mathbf{T}$ and $\mathbf{L}$ take values equal to one in, respectively, the winter, period, and location in which the violence took place, and zero otherwise. Let us define being affected by violence as $V_{W T L}=\mathbf{W} \times \mathbf{T} \times \mathbf{L}$, and let $V_{W T}=\mathbf{W} \times \mathbf{T}$. The coefficient of interest is $\widehat{\gamma}_{D D D}$, which provides an estimate of whether, relative to the previous winters and accounting for seasonality, exports of firms in the violence-affected areas behaved differently from exports in the no-violence areas during the period of the violence. All columns in Table 3 include these covariates, with progressively less restrictive assumptions.

Column (1) reports the triple difference estimate allowing for different intercepts for the day of the year, the particular day of the week, and the winter. Column (2) builds on the previous specification controlling for firm fixed effects. Column (3) allows for different winter fixed effects in the violence and no-violence areas (that is different growth across the violence and the no-violence regions between successive winters). As mentioned above, the

\footnotetext{
${ }^{30}$ From the point of view of statistical inference, there are two main concerns. First, production and, therefore, shipments of flowers of a given firm are likely to be correlated within each firm, even conditional on the fixed effect. If shipment to a particular buyer has occurred today, it is less likely that another shipment to the same buyer will occur tomorrow. Second, across firms, error terms are likely to be correlated because firms are geographically clustered and, therefore, shocks to, e.g., roads and transport, are correlated across neighboring firms. Throughout the analysis using transaction-level data, therefore, standard errors are clustered both at the firm and the season-week-location level using the Cameron et al. (2011) procedure.
} 
floriculture trade is seasonal and the seasonality could be different across locations. Column (4) allows flexibility in the seasonal patterns across regions by defining seasonality at the date level.

Column (4) is our primary specification. The coefficient of interest $\widehat{\gamma}_{D D D}$ for both the first and second outbursts of violence are very similar in magnitude to those estimated in Table [2].

Parallel Trends. The results in column (4) are graphically illustrated by Figure 3. The figure plots the (median) residuals of the corresponding baseline regression for firms in the violence and in the no-violence regions, when the violence terms $V_{W T}$ and $V_{W T L}$ are not included in the specification. The figure further supports the identification strategy: we do not find any evidence of differences in trends or behavior across regions in the weeks leading up to the violence.

Firm-Specific Growth and Seasonality. Finally, columns (5) and (6) allow for firmspecific seasonality patterns and firm-specific growth between winters and show that the estimates of the impact of the violence are robust to allowing flexible growth and seasonality patterns across firms. Due to the large number of fixed effects being estimated, the statistical significance is somewhat reduced in column (6).

As noted above, using the no-violence region as a control group could lead to estimates contaminated by spillover effects. Panel B of Table [3], therefore, repeats the same specifications as in panel A focusing exclusively on the firms located in the violence regions. The resulting estimates are very similar to those in panel A once the extensive set of covariates is used, suggesting that spillovers are of relatively small magnitude. Panel $\mathrm{C}$ provides more direct difference-in-difference evidence on a possible effect of the violence on the control locations. This first placebo test shows that there is no overall effect on the control areas, at least not compared with previous seasons and relative to the pre-election period, on average.

\subsection{Robustness checks}

In addition to controlling for seasonality of exports, export growth over time, and location of conflict, we conduct additional robustness checks that assess possible alternative explanations of the observed patterns. Specifically, we (1) investigate the effect of moving away from using a binary categorization of locations into conflict and no-conflict areas, (2) assess whether infrequent exporters and traders exported additional flowers during this time, (3) investigate 
location-specific growth and seasonality, and (4) conduct a placebo analysis for the period prior to the conflict.

Violence Intensity and Localization. In Table 44, we assess the robustness of the binary categorization of firms into violence versus no-violence areas by allowing for the intensity and the influence area of the conflict to vary. We use the Armed Conflict Location and Event Data Project (ACLED) as an alternative source of conflict data. This project geo-codes all instances of political violence and protest within developing countries and hence also covers episodes of election violence.

The table provides evidence on the effect of violence at different radii from the flower firm premises $(5 \mathrm{~km}, 10 \mathrm{~km}$ and $20 \mathrm{~km})$ and of the intensity of violence. Columns 1 to 9 show that the effect of violence is very localized. We find a statistically significant effect of any report of violence (or any report of fatal violence) in a $10 \mathrm{~km}$ radius, but not at a $20 \mathrm{~km}$ radius from the flower firms' premises.31

Columns 10 to 12 , however, consider a definition of the violence that takes into account the number of fatal accidents. Results indicate that there is no statistically significant relationship between the number of fatalities and the drop in export. We interpret this as evidence that rather than the violence itself, it is the associated disruptions and workers' worries due to the fear of violence and associated insecurity that leads to the drop in production.

Traders and Infrequent Exporters. One potential concern for our empirical strategy, which relies on using detailed information on established flower exporters to be able to match export activity to the location of the violence - is that it omits exports of firms who are not established exporters or for whom we do not have location information that would allow us to assign them into a violence or no-violence group. This is the case for flower traders, for which we do not have information on the location of the farms they source flowers from. Similarly, there are a few infrequent exporters for whom we have export records over the prior years, and there could have been exports by new entities during this period. Appendix Figure B3] shows the total exports of these excluded exporters. Their overall exports are low, and we do not find any pattern of concern that would suggest that traders may have exported additional amounts of flowers during this period.

Placebo and Further Tests. The empirical strategy that underlies much of our analysis

\footnotetext{
${ }^{31}$ We are able to geo-locate flower firms using Google Maps and industry reports, details are provided in Appendix D,
} 
relies on the assumption that there is nothing special about flower supply in the violence area during the time of the conflict that is not related to the violence. While we cannot test that assumption directly, we can assess whether exports of firms located in the violence area appear different just before the election. Appendix Table C3 shows that there is no differential pattern in exports in the weeks leading up to the election and violence.

To address concerns that there might be location-specific patterns of seasonality and growth, Appendix Table [C4] shows that the results are robust to accounting for locationspecific seasonality effects. Due to the large number of fixed effects, several of the results are less precisely measured, but the magnitude is very close to those in our main Table [2].

Effects on Other Firm Outcomes. Appendix Table C5 presents results for other outcomes. Column (1) presents the estimate for daily export data and our baseline specification again as in column (4) of Table [3]. The negative effects on export volumes in a given day can be decomposed into two effects: a decrease in the likelihood of exporting, i.e., the extensive margin, (column (2)) and a decrease in the export volumes conditional on exporting, i.e., the intensive margins (column (3)).

Results indicate that the second outbreak of violence had a negative and significant impact on a firm's ability to export, while the negative point estimate is not significant for the first period of violence. During both episodes, the export volumes conditional on exporting decreased as a consequence of the violence, but not significantly so. An extension of the model presented in Appendix $\mathrm{A}$ has ambiguous predictions for the conditional export volumes, since flowers can, though not ideally, be harvested a day or two earlier or later. Column (4) shows that the unit value in Kenyan shillings (in logs) increased during both episodes of violence. This result, however, simply captures the substantial depreciation of the Kenyan currency during the violence. The Kenyan shilling went from a high of 90 KShs/Euro prior to the presidential elections to an exchange rate of $100 \mathrm{KShs} /$ Euro during the first outbreak and depreciated further to $108 \mathrm{KShs} /$ Euro during the second outbreak of violence. Unreported results confirm that unit values in Euros did not change during the violence. Furthermore, these results confirm that there was no differential effect on unit values in Kenyan shilling across regions at the time of the violence.

Column (5) documents that there was no effect of the violence on unit weight either. In the case of roses, which represent the vast majority of flowers exported from Kenya, a key determinant of a flower's value is its size which is, in turn, determined by the altitude at which the firm is located. Firms are, therefore, relatively specialized in the size of flowers grown and the evidence confirms that the violence did not affect the composition of exports. 
Medium-Run Effects. The violence dummies are defined for the short (i.e., five- to six-day) periods that correspond precisely to the two spikes of violence. For several reasons, however, it is interesting to consider a longer definition during which violence may have affected exports. First, sporadic violence occurred throughout the month of February 2008. While not directly affecting firms' operation, the violence could have created an uncertain business climate that may have had indirect effects on the industry. Second, (though none of our respondents mentioned this) firms might have tried to store flowers or intensify production in the days immediately following the violence in hope of recovering the losses. Finally, it is interesting to see whether the violence had medium-run effects on the firms (e.g., because of damage to a firm's assets, such as plants, due to workers' absence). Appendix Figure [B4] reports the cumulative and the medium run-effects of the violence throughout the month of February 2008. While the cumulative effect remains negative and shows that firms never recovered the losses in production incurred during the time of the violence, the figure also shows that in about one week to 10 days after the end of the second spike, firms were not suffering any significant medium-run effects of the violence. The relatively short delay in recovery is consistent with workers returning to their jobs shortly after the violence ended.

\subsection{The Violence as a Supply Shock: Mechanisms}

This section investigates the mechanisms through which the violence affected firms. First, using the survey, we corroborate the violence indicators used in the previous section and show that firms in locations classified as having suffered from the violence are more likely to report to have worker absence, experienced transportation problems and hired security. Second, we explore heterogeneity in the response to the violence and test the predictions of the model. We then explore the role of workers' absence and transportation problems in affecting firms' performance during the violence. Finally, we attempt to quantify the short-run losses incurred by firms during the violence.

Incidence of the Violence: Survey Responses. Before turning to the evidence on production, Table 5 shows that survey responses about the violence are very strongly correlated with the definition of the violence region that we have used in the reduced form specifications above. In particular, we find that firms located in the violence regions are significantly more likely to report that (i) their operations have been directly affected by the violence (column 1), (ii) there were days in which members of staff did not come to work because of 
the violence (column 2), (iii) the firm experienced a higher proportion of workers absence due to the violence (column 3), (iv) worker absence caused significant losses in production (column 4), (v) the firm experienced transportation problems in delivering flowers to the airport (column 5) and, finally, (vi) the firm hired extra security personnel during the violence period (column 6).

Heterogeneity in Workers and Export Losses. We now test the model's predictions exploring heterogeneity across firms. Table [6] reports cross-sectional correlations between the firms' characteristics and the percentage of workers absent at the peak of the crisis for firms in the violence location. While firms in the violence and no-violence regions appear to be broadly comparable along observable characteristics (see Table [1]), the same is not true across locations within the violence and no-violence regions. Since locations also differ in the intensity of the violence, the specification includes location dummies as controls.

Consistent with the predictions of the model, Table [6] shows a correlation between the marketing channels and (in most specifications) the size of the firm and the percentage of workers absent during the violence. In particular, among firms located in the regions affected by the violence, we find that firms exporting through the auctions and smaller firms report a higher fraction of workers missing during the violence period. The correlation between marketing channel and size is robust to the inclusion of a large number of covariates, including (i) location dummies to account for the intensity of the violence, (ii) dummies for housing, social programs, and fair-trade-related certifications, (iii) the gender composition of the labor force, (iv) owners' identity, (v) product variety, and (vi) proxies for capital invested in the firm.

The results could, in principle, be driven by systematic differences in the composition of the labor force across firms. For example, firms employing a higher percentage of the minority group in a given locality might suffer higher worker and export losses. In column (7) we include a measure of the proportion of the workforce that is at risk of violence. We define being at risk as being a member of an ethnic group that was in the opposite alliance from the majority ethnic group of the location. While this proportion at risk is positively correlated with a higher proportion of workers lost, the effect is not precisely estimated.

Table 7 reports the heterogeneity results in exports. We focus on the second outbreak of violence (as in panel B of Table 22) since the small number of firms affected during the first period of violence (20) precludes the estimation of heterogeneous effects. We include the firms' characteristics as in Table [6] interacted with the violence period dummy. For ease of exposition, the table only reports the coefficients on the interactions between the shock 
and the firms' characteristics of interest.

The evidence supports the predictions of the model with respect to firm size and marketing channels: on average, smaller firms and firms exporting through the auctions suffered a greater reduction in export volumes during the violence. ${ }^{32}$ The last column in the table shows that these correlations are robust to controlling for several other firms' characteristics. Similar to the results in Table [6, we find that the proportion of workers at risk is not significantly correlated with the size of the effect of the violence.

In sum, the results of the heterogeneity analysis appear to be broadly consistent with the predictions of the model. The results must, of course, be interpreted cautiously and, in particular, care should be taken before interpreting the estimates in Tables [6] and Table [7] as causal effects of firm size or marketing channel on exports and worker retention during the violence. Unobservable characteristics might correlate with a firm's exposure, or capacity to react, to the violence as well as with the firm's size and marketing channels. The extensive set of firms' characteristics we can control for assuages, to some extent, these concerns.

Mechanisms: Worker Absence and Transport. In the firm interviews we asked, on a week-by-week basis for the period covering January and February 2008, (i) how many workers were absent, and (ii) whether the firm suffered transportation problems. We now use these measures to provide suggestive evidence on the relevance of these two mechanisms.

Before describing the results, it is worth pointing out certain limitations of this exercise. The retrospective nature of the survey might introduce measurement error in the form of imperfect recall or even bias. For example, respondents may be more likely to recall worker absence as a problem if they were located in the violence region and have more salient memories of worrying about worker absenteeism. Furthermore, the extent of measurement error could be different between reported worker absence and transportation problems.

Although we cannot provide any evidence to assuage such concerns, the interviews we conducted in person left us with reassuring impressions. The events we asked about took place six months before the survey but were still very salient to the respondents. Responses on transportation difficulties appear to correlate well across respondents within narrowly defined localities, as expected. With respect to workers' absence, we asked respondents to check payroll records 33

\footnotetext{
${ }^{32}$ Although firms that export directly suffer lower reductions in exports than firms exporting through the auctions, the estimates imply an overall reduction in exports for both types of firms. In a sample of wellestablished relationships, Macchiavello and Morjaria (2015) estimate a 17\% drop in exports in the average relationship. Section 4.4 explores how international buyers in direct relationships react to the shortfall.

${ }^{33}$ We could not access the payroll records directly and, unfortunately, we did not take note during the
} 
A second caveat to this analysis is that both the percentage of workers absent and, possibly to a lesser extent, transportation problems experienced by the firm are likely to be, at least in part, the result of an endogenous response by firms to the violence and insecurity.

Notwithstanding these caveats, Appendix Table [C6] reports the results. Specifications are analogous to those in previous tables, but note that the regressions are estimated on the sample of interviewed firms only and the unit of observation is at the firm-week level since the survey variables were asked on weekly basis. Column (1) simply recovers an average reduced form effect of the violence at the week level. The estimated coefficient is similar to the estimates obtained in previous specifications. Columns (2) and (3) show that the time-varying self-reported measures of worker losses and transportation problems correlate with lower exports. In all cases, estimated coefficients are negative, economically sizeable, and statistically significant at conventional level.

Column (4) considers the three variables together to quantify the relative importance of workers' absence, transportation problems, and the general situation related to the violence in the location of the firm. All estimated coefficients drop by about half and are no longer statistically significant at conventional level. The results thus suggest that it is difficult to statistically attribute the overall effects on exports to specific channels. In the survey, however, only $50 \%$ of firms in the conflict areas report transportation difficulties, while almost $90 \%$ report worker absenteeism due to the violence. To gauge the extent to which worker absence affected exports, column (5) restricts the sample in the violence regions to those firms that did not experience transportation problems. Interestingly, the point estimate is indistinguishable from the one estimated using the full survey sample in column (2). Although the change in sample warrants caution in interpreting the results, the evidence is consistent with worker losses having been a very important mechanisms through which the violence affected exports.

Quantifying Losses During the Violence. We now attempt to quantify firms' losses during the violence. The model provides guidance on how firm-specific reduced form estimates of the effects of the violence on production, $\Delta^{v}$, can be combined with knowledge of the firm's revenues per worker during normal times, $R^{*}$, and estimates of $\eta$ and $\gamma$ to provide a back-of-the-envelope calculation of the effects of the violence on firms' profits.34

interviews about whether the respondent consulted payroll records. Looking at the survey, some respondents provided precise numbers for workers' absence while other responses do suggest that the interviewee used focal categories, suggesting measurement error. Whether the measurement error is exacerbated by recall bias would be an open question.

${ }^{34}$ In the survey we also tried to elicit revenue losses and increases in costs, but the reported figures appear 
Weekly revenues per worker $R^{*}$ in normal times are easily computed, for each firm, by dividing a firm's export revenues in normal times, proxied by the median weekly revenues during the 10 weeks control period that preceded the violence (which are available from trade transaction records), by the number of workers employed by the firm (which is available, for the same period, from the survey).

We assume that the parameters $\gamma$ and $\eta$ are identical across firms. From the expression of profits in normal times it follows that the share of wage costs in revenues is equal to $\psi=\frac{1}{1+\gamma}$. Information collected in the survey suggests $\psi \simeq 0.2$ for a typical firm, implying $\gamma \simeq 4$. Note that weekly earnings per worker in normal times are equal to $y^{*}=\frac{1}{\gamma+1} R^{*}$. With $\gamma=4$, this gives $\widehat{y}^{*} \simeq 1250$ Kenyan shillings for workers at the median firm (or 14 Euro at pre-violence exchange rates) ${ }^{35}$

With knowledge of $\gamma, \eta$ can be recovered estimating equation (7). The equation is the analogue of the specification in Table [6], with the log of the share of retained workers replacing the share of missing workers. Unreported results, show that the estimated coefficient, $\widehat{\beta}=\frac{\eta(1+\gamma)-1}{\gamma}$, is equal to 0.45 , implying $\widehat{\eta}=0.56$ when $\gamma=4$.

Finally, the reduced form effect of the violence on production $\Delta^{v}$ is given by the firmlevel difference-in-difference as computed in Table [2], which corresponds to equation (11). Note that, since both the reduced form effect of the violence on production, $\Delta^{v}$, and the revenues per worker in normal times, $R^{*}$, are available for each firm separately, the model can be calibrated for each firm. By comparing the share of retained workers reported in the survey with the corresponding estimates from the model calibration, it is possible to further validate the consistency of the model with the data. Results show a 0.73 correlation between the two variables, which is statistically significant at the $1 \%$ level.

Results for the median firm (out of the 37 surveyed in the conflict regions with complete information) are as follows. The drop in production was 56\%. Prices in export markets were not affected by the violence but the Kenyan shilling depreciated by about $10 \%$. Revenues in domestic currency dropped by only $10 \%$. The calibration reveals that labor costs in Kenyan shillings increased by $83 \%$ on average but, given the low share of the wage bill in

to be noisy. Besides sources of measurement error described above, a concern is that some respondents might have inflated losses to influence the business association (with whom we would have shared a report on our findings) to lobby the government for compensation and additional support.

${ }^{35}$ This estimate nicely matches prevailing wage rates in the flower industry at the time of the survey. These were (about) 200 Kenyan shillings per day immediately before the violence, implying weekly earning of around 1200 Kenyan shillings. For this reason, we take $\gamma=4$ as our preferred estimate. Results are robust using alternative choices of $\psi$ in the range $\psi \in[0.1,0.25]$. 
total costs, this translates into a $19 \%$ increase in costs ${ }^{36}$ The median firm would thus have made losses during the violence unless operating profit margins were at least $22 \%$, quite a large number. The estimates thus suggest that the median firm in the violence region likely operated at a loss during the violence ${ }^{37} 38$

\subsection{Demand-Side Reaction to the Violence}

The evidence suggests that the violence was a large, negative, supply shock to the firms that were affected. Given this negative supply shock, how did the demand side of the market adjust?

Despite the large shock in Kenya, prices at the auction markets in the Netherlands, which consolidate demand and supply across the globe, were not hugely affected by the violence. At the time of the violence Kenya accounted for about $10 \%$ of the world's exports of flowers. The violence hit half of Kenya's industry, reducing exports by about 30\%. This implies that the violence caused a relatively small drop in the aggregate supply of flowers at the Dutch auctions. We thus focus on the response of global buyers sourcing through direct relationships. These buyers suffered an average reduction in deliveries of about $17 \%$ (see Macchiavello and Morjaria (2015)). We now consider their ability to cope with this shock by shifting sourcing to other suppliers in Kenya and abroad that were not directly affected by the violence.

Sourcing from No-Conflict Areas in Kenya. For an international buyer regularly sourcing flowers from firms hit by the violence in Kenya, a first response margin would have been to try to increase sourcing from Kenyan suppliers not directly affected by the violence. Besides its intrinsic interest, exploring this channel also allows us to discuss potential spillover across regions. Table [2] column (1), and Table 3] panel $\mathrm{C}$ document that on average firms

\footnotetext{
${ }^{36}$ The figure includes both the wages paid for the extra hours worked at the farm for the remaining workers as well as costs incurred to get workers to come to work but does not include other fixed costs (e.g., hiring of extra security). The interviews, however, revealed that those costs were small.

${ }^{37}$ During the violence period, firms were building up towards Valentine's Day and might have had additional workers on their payroll who might not have been employed at full capacity. If so, the results might underestimate the impact of the violence since it could have been relatively easier for certain firms to adjust relative to other times in the season.

${ }^{38}$ With respect to heterogeneity, the survey and the calibration yield rather inconclusive answers as to whether or not firms selling through direct relationships incurred higher profit losses. Conditional on firms' characteristics included in Table 6], the survey reveals that the percentage sold in direct relationships correlates with higher costs (p-value 0.10), lower losses in revenues (p-value 0.33) and higher profit losses (p-value 0.10). While these estimates are consistent with the model, they are noisy and somewhat sensitive to sample selection and outliers.
} 
in the conflict areas did not export more flowers relative to prior seasons and prior years. This suggests that spillovers, if any, do not pose a severe threat to the identification of the reduced form average treatment effect of the violence. The average finding, however, could be hiding two opposing effects. First there might be negative spillovers on firms due to a countrywide effect of the insecurity. Second, there might be a positive spillover if some firms in the no-conflict area benefited from additional demand for their flowers.

To explore this hypothesis, we focus on buyer-firm relationships in which the buyer sourced from firms in both the conflict and no-conflict area. We test for whether buyers who were sourcing from exporters located in the conflict area were able to source additional flowers from firms in the no-conflict area. Table 8 presents the results focusing on buyer-seller pairs that had relationships before the onset of the violence. Increases along the intensive margin of trade provides the best path to find evidence of positive spillover since the data reveal that none of the 64 buyers that exclusively sourced from the conflict region before the violence was able to start sourcing from the no-conflict region during the shock. In total, 48 buyers were sourcing in both regions before the violence.

The table explores both specifications with firm and buyer fixed effects (columns (1) and (3)), as well as specifications in which we condition for buyer-seller pair fixed effects (columns (2) and (4)). Columns (1) and (2) consider a continuous measure of exposure, defined as the share of flowers imported from Kenya that the buyer sourced in the conflict region. Columns (3) and (4) instead consider a simple indicator for whether the buyer was sourcing any flower at all from the violence region. All specifications include day-of-year, day-of-week and winter fixed effects.

Across the board, we find that buyers that were sourcing from the conflict region were not able to shift their sourcing to exporters located in the no-conflict region. Although the estimated coefficient is positive, it is small and far from being statistically significant in all the specifications.

Sourcing from Ethiopia. International buyers sourcing in Kenya at the time of the violence had a second potential margin of adjustment: increase imports from other origins. The closest substitutes for Kenyan flowers is nearby Ethiopia, a country with a burgeoning flower export industry of its own and that has consciously supported the development of the sector through an active industrial policy ${ }^{39}$ Using detailed trade transaction data from Ethiopia, we analyze whether international buyers that were exposed to the violence in Kenya

\footnotetext{
${ }^{39}$ See Antić and Morjaria (2020) for additional details on the Ethiopian context and data description.
} 
were able to increase sourcing from the country. Besides its usefulness for understanding buyers' response, the analysis also has potentially important welfare implications. Globally, the negative welfare impacts of the violence may well be less if other countries are able to compensate for reduced Kenyan exports by exporting more.

Table 9] reports the results. Among the 99 international buyers sourcing from Ethiopia just before the violence, only 16 were also sourcing from Kenya and 9 specifically from the regions affected by the violence 40 We consider both separately. Note that, consistent with the evidence from Kenya in Table [8], none of the buyers sourcing flowers in Kenya but not Ethiopia just before the violence was able to start sourcing in Ethiopia.

The empirical specifications are similar to those in Table 8, and consider both the continuous and discrete definition of exposure to Kenya in general, and to the regions with the violence in particular. For simplicity, we focus on specifications that include buyer-seller pair fixed effects, but results are qualitatively identical when considering the two sets of fixed effects separately. Across the board, we find that no evidence that international buyers were able to relocate supplies from Kenya to Ethiopia on short notice 41

Medium-Term Effects of the Violence. In sum, the available evidence suggests that, to a large extent, international buyers were unable to easily shift sourcing to respond to supply-chain disruptions caused by the violence. This evidence is consistent with the findings in Macchiavello and Morjaria (2015), which establish that exporters value maintaining a reputation for reliable deliveries to their existing buyers and that it takes time to establish new relationships.

The violence might have had additional medium-term impacts. In the flower industry, contracts with direct buyers are renegotiated at the end of the summer. Within firms, relationships that were not prioritized by the firm during the violence are more likely to break down and not survive to the next season relative to relationships that were prioritized by the firm. From the firm perspective, however, the overall impact was modest. This is likely due to the possibility of selling to the auctions and forming new relationships. In particular, we check survival rates in the industry one year and two years after the violence. We consider firms located in the conflict region and those located in the no-conflict region. We further split the groups between firms that, at the time of the violence, were predominantly selling

\footnotetext{
${ }^{40}$ These figures suggests that relatively few buyers diversify their sourcing origins in the industry. similar patterns are observed in the Ethiopian floriculture industry, see Antić and Morjaria (2020).

${ }^{41}$ The estimated coefficients using the continuous definition of exposure appear large (although indistinguishable from zero) but simply because the average exposure measure is low. They thus imply very small economic magnitudes.
} 
through direct relationships versus those that predominantly sold to the auctions. We find no statistically significant difference in survival rate and export performance across the four groups two years after the violence.

Mitigating Supply-Chain Risk: Evidence from Kenya's 2013 Election. The evidence thus suggests that it is difficult for international buyers to cope with supply-chain disruptions when they occur. If this is the case, we might expect firms to take precautionary measures when the risk of supply-chain disruptions increase.

Although the industry fully recovered from the short-lived violence in 2008, the violence might have cast a long shadow into the future. Specifically, it is possible that the violence changed firms' expectations of post-election violence. We analyze whether Kenyan flower firms (and their buyers) changed the schedule and volume of exports in possible anticipation of violence around the presidential elections that took place on March 4, 2013. This would also document whether buyers and firms expected violence or disruptions.

We begin by estimating a countrywide difference-in-differences specification similar to columns (1) and (2) in Table [2] but for the entire country. We define the potential period of violence as the period after March 4, 2013 ${ }^{42}$ Figure [4 visually suggests that there is a change in behavior of exporters taking place, and columns (1), (3) and (5) of Table [10] show that these changes are statistically significant.

We also investigated whether these expectations of violence reacted to the patterns of violence in 2008 - that is, whether firms located in areas in which there was violence in 2008 changed their behavior. We do not find any evidence of a location-specific effect. This may be explained by the fact that the ethnic compositions of the two coalitions changed across the two elections, so the fault lines would not have been the same as in 2008 .

Because firms have a much stronger incentive to maintain relationships we observed differences in exporting behavior by marketing channel in 2008, we also analyze whether such differences can be observed in 2013. Panel B of Figure 4 shows the share of a firm's exports going to direct buyers versus the auction. We find that firms did prioritize exports to direct buyers in the days before the election, while there is a visible dip in the share of exports to firms just after the election.

While this pattern is precisely measured (see columns (2), (4) and (6) of Table [10]), the overall effect is statistically significant but relatively small. We conducted phone interviews with a few exporters before the election to gather qualitative information about their

\footnotetext{
${ }^{42}$ The 2013 presidential elections occurred just over 5 years and 3 months after the previous election at the end of 2007.
} 
behavior. The phone interviews suggest that many firms did not perceive the risk of a repeat of the 2008 post-election violence to be particularly high in 2013. Those who did reported that flowers are perishable and have a limited shelf life, and thus adjustments in the schedule of shipments were limited and restricted to buyers with adequate facilities to store flowers.

\section{Conclusions}

This paper combined detailed administrative records on production, an original firm survey, and several other data sources, to understand how post-electoral violence in 2008 affected the Kenyan flower industry.

On the supply side, the results show that the violence induced a large negative shock. After controlling for firm-specific seasonality patterns and growth, weekly export volumes of firms in the affected regions dropped, on average, by $56 \%$ relative to what would have happened had the violence not occurred. Consistent with the predictions of our model, large firms and firms with stable contractual relationships in export markets registered smaller percentage losses in production. These firms also reported smaller percentages of workers missing during the time of the violence.

On the demand side, international buyers were not able to compensate the reduction in deliveries by increasing sourcing from either Kenyan exporters located in areas not directly affected by the violence nor from neighboring Ethiopian suppliers. Consistent with difficulties in insuring against supply-chain risk disruptions caused by electoral violence, exporters and buyers in direct contractual relationships mitigated risk by ramping up shipments just before the subsequent presidential election.

Taken together, the results have implications for policy makers and business executives alike. From a policy perspective, the findings from this study are relevant to countries interested in fostering nontraditional agricultural value chains. For example, the success of floriculture in Kenya has led several Sub-Saharan countries, most notably Ethiopia (see Antić and Morjaria (2020)), but also Tanzania, Uganda, Zambia, and Rwanda among others, to promote the development of the industry. Our results suggest that incentives associated with stable relationships in nontraditional agriculture encouraged firms to quickly respond to the violence. ${ }^{43}$ Stable relationships might be associated with higher exporters' margins

\footnotetext{
${ }^{43}$ This suggests that the negative effects of the violence might be even larger in traditional agriculture value chains in which domestic traders and processors market the fresh produce of smaller farmers, often for the local market.
} 
(see Cajal-Grossi et al. (2019) but can also lead to foreclosure and less competitive conduct (see, e.g., Boehm and Sonntag (2020)). While this study does not provide a comprehensive evaluation of the social benefits of such export arrangements, it provides a novel rationale for why policy makers in countries prone to instability might promote the adoption of such arrangements among exporters ${ }^{44}$ The results also have implications for business executives organizing sourcing from politically unstable environments. In particular, the same market frictions, such as search costs and limited contract enforcement, that make stable relationships with suppliers valuable can also hinder buyers' ability to cope with disruptions by swiftly shifting sourcing to alternative suppliers. Diversifying sourcing origins and planning precautionary measures when risks of disruptions increase become essential tools of the trade.

\section{References}

Abadie, Alberto and Javier Gardeazabal, "The Economic Costs of Conflict: A Case Study of the Basque Country," American Economic Review, 2003, 93 (1), 113-132.

Akresh, Richard and Damien De Walque, "Armed Conflict and Schooling: Evidence from the 1994 Rwandan Genocide," Policy Research Working Paper 4606, The World Bank 2008.

Alesina, Alberto, Sule Özler, Nouriel Roubini, and Phillip Swagel, "Political Instability and Economic Growth," Journal of Economic Growth, 1996, 1 (2), 189-211.

Amodio, Francesco and Michele Di Maio, "Making Do with What You Have: Conflict, Input Misallocation, and Firm Performance," The Economic Journal, 2017, 128 (615), 2559-2612.

_ , Leonardo Baccini, and Michele Di Maio, "Security, Trade, and Political Violence," Technical Report IZA Discussion Papers No. 10819, Institute of Labour Economics (IZA), Bonn 2017.

Antić, Nemanja and Ameet Morjaria, "Searching for New Markets by Ethiopian Exporters," Working Paper, Kellogg School of Management 2020.

\footnotetext{
${ }^{44}$ From a broader perspective, Hernandez (2015) finds that the growth of the flower sector was associated with lower rates of unorganized violent crime but no change in guerrilla warfare in Colombia. In the African context, the development of the flower industry has created job opportunities in rural areas but might have exacerbated tensions over land and water.
} 
Barrot, Jean-Noël and Julien Sauvagnat, "Input Specificity and the Propagation of Idiosyncratic Shocks in Production Networks," The Quarterly Journal of Economics, 2016, 131 (3), 1543-1592.

Bates, Robert, Prosperity and Violence: The Political Economy of Development, New York, USA: W. W. Norton \& Company, 2001.

_, When Things Fell Apart: State Failure in Late-Century Africa, New York, USA: Cambridge University Press, 2008.

Besley, Timothy and Torsten Persson, "The Incidence of Civil War: Theory and Evidence," 2008. mimeo, LSE and IIES, Stockholm.

Blattman, Christopher and Edward Miguel, "Civil War," Journal of Economic Literature, 2010, 48 (1), 3-57.

- and Jeannie Annan, "The Consequences of Child Soldiering," Review of Economics and Statistics, 2010, 92 (4), 882-898. forthcoming.

Blouin, Arthur and Rocco Macchiavello, "Strategic Default in the International Coffee Market," The Quarterly Journal of Economics, 2019, 134 (2), 895-951.

Blumenstock, Joshua, Tarek Ghani, Sylvan Herskowitz, Ethan B. Kapstein, Thomas Scherer, and Ott Toomet, "Insecurity and Industrial Organisation: Evidence from Afghanistan," Policy Research Working Paper No. 8301, World Bank, Washington, DC 2018. License: CC BY 3.0 IGO.

Boehm, Johannes and Jan Sonntag, "Vertical Integration and Foreclosure: Evidence from Production Network Data," 2020.

Bratton, Michael and Mwangi S. Kimenyi, "Voting in Kenya: Putting Ethnicity in Perspective," Journal of Eastern African Studies, 2008, 2, 272-289.

Burgess, Robin, Remi Jedwab, Edward Miguel, Ameet Morjaria, and Gerard Padró i Miquel, "The Value of Democracy: Evidence from Road Building in Kenya," American Economic Review, 2015, 105 (6), 1817-1851.

Cajal-Grossi, Julia, Rocco Macchiavello, and Guillermo Noguera, "International Buyers' Sourcing and Suppliers' Markups in Bangladeshi Garments," 2019. 
Cameron, Colin A., Jonah B. Gelbach, and Douglas L. Miller, "Robust Inference with Multi-way Clustering," Journal of Business \&3 Economic Statistics, 2011, 29 (2), $238-249$.

Carvalho, Vasco M, Makoto Nirei, Yukiko Saito, and Alireza Tahbaz-Salehi, "Supply chain disruptions: Evidence from the great east japan earthquake," Quarterly Journal of Economics, 2021, (forthcoming).

Catholic Justice and Peace Commission, An Investigative Report on Post Election Violence in Kenya 2008.

Collier, Paul, The Bottom Billion: Why the Poorest Countries are Failing and What Can Be Done About It, New York: Oxford University Press, 2007.

- and Anke Hoeffler, "On Economic Causes of Civil War," Oxford Economic Papers, $1998,50,4$.

- and Marguerite Duponchel, "The Economic Legacy of Civil War: Firm Level Evidence from Sierra Leone," Journal of Conflict Resolution, 2013, 57 (1), 65-88.

Dercon, Stefan and Roxana Gutiérrez-Romero, "Triggers and Characteristics of the 2007 Kenyan Electoral Violence," World Development, 2012, 40 (4), 731-744. ISSN 0305$750 \mathrm{X}$.

Dube, Oeindrila and Juan F. Vargas, "Commodity Price Shocks and Civil Conflict: Evidence From Colombia," The Review of Economic Studies, 2013, 80 (4 (285)), 13841421.

Dupas, Pascaline and Jonathan Robinson, "The (Hidden) Costs of Political Instability: Evidence from Kenya's 2007 Election Crisis," Journal of Development Economics, 2012, 99 (2), 314-329. ISSN 0304-3878.

Gibson, Clark C. and James D. Long, "The Presidential and Parliamentary Elections in Kenya, December 2007," Electoral Studies, 2009, pp. 1-6.

Glick, Reuven and Alan M. Taylor, "Collateral Damage: Trade Disruption and the Economic Impact of War," Review of Economics and Statistics, 2010, 92 (1), 102-127.

Guidolin, Massimo and Eliana La Ferrara, "Diamonds Are Forever, Wars Are Not: Is Conflict Bad for Private Firms?," American Economic Review, 2007, 97 (5), 1978-1993. 
Hernandez, Sarah, "Guns N'Roses: The Impact of Female Employment Opportunities on Violence in Colombia." PhD dissertation, Thesis: PhD, Massachusetts Institute of Technology, Department of Economics 2015.

Hjort, Jonas, "Ethnic Divisions and Production in Firms," Quarterly Journal of Economics, 2014, 129 (4), 1899-1946.

Independent Review Commission, Report of the Independent Review Commission on the General Elections held in Kenya on 27th December 20072008.

Kenya National Commission on Human Rights, "On the Brink of the Precipice: A Human Rights Account of Kenya's Post-2007 Election Violence," 2008. Nairobi, Kenya.

Kenya Red Cross Society, "Information Bulletins (01 January 2008 - 04 March 2008)," 2008. Last accessed on 22 September 2008.

Kimenyi, Mwangi S. and William F. Shughart, "The Political Economy of Constitutional Choice: A Study of the 2005 Kenyan Constitutional Referendum," Constitutional Political Economy, 2010, 21 (1), 1-27.

Klapper, Leora, Christine Richmond, and Trang Tran, "Civil Conflict and Firm Performance : Evidence from Cote d'Ivoire," Policy Research Working Paper No. WPS 6640, World Bank, Washington, DC 2013.

Korovkin, Vasily and Alexey Makarin, "Trading with the Enemy: The Impact of Conflict on Trade in Non-Conflict Areas," 2019. Working Paper.

León, Gianmarco, "Civil Conflict and Human Capital Accumulation: The Long Term Effects of Political Violence in Perú," Journal of Human Resources, 2010, 47 (4), 9911022. Mimeo, Berkeley.

Macchiavello, Rocco and Ameet Morjaria, "The Value of Relationships: Evidence from a Supply Shock to Kenyan Rose Exports," American Economic Review, September 2015, $105(9)$.

Martin, Philippe, Thierry Mayer, and Mathias Thoenig, "Civil Wars and International Trade," Journal of the European Economic Association, April-May 2008, 6 (2-3), $541-550$. 
Miguel, Edward and Gérard Roland, "The Long Run Impact of Bombing Vietnam," Journal of Development Economics, 2011, 96 (1), 1-15.

Montoya, Eduardo, "Violence and Economic Disruption: Firm-level Evidence from Mexico," 2016. Technical report, Working Paper.

Morjaria, Ameet, "Democracy and the Environment: Evidence from Kenya," Working Paper, Kellogg School of Management 2018.

Nitsch, Volker and Dieter Schumacher, "Terrorism and International Trade: an Empirical Investigation," European Journal of Political Economy, 2004, 20 (2), 423-433.

Rodrik, Dani, "Growth Strategies," in P. Aghion and S. Durlauf, eds., Handbook of Economic Growth, Vol. 1, Elsevier, 2005, pp. 967-1014.

Rozo, Sandra V., "Is Murder Bad for Business? Evidence from Colombia," The Review of Economics and Statistics, 2018, 100 (5), 769-782.

Straus, Scott and Charlie Taylor, "Democratization and Electoral Violence in SubSaharan Africa, 1990-2007," 2009. APSA Toronto Meeting Paper. 


\section{Figures}

\section{Figure 1: Elections and Violence in Sub-Saharan Africa, 1990-2018}

Panel A: Violence any time during an election year

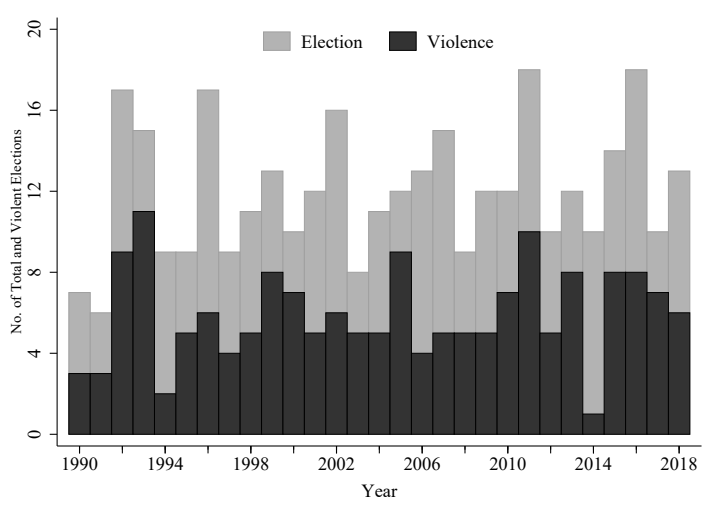

Panel B: Violence post-election

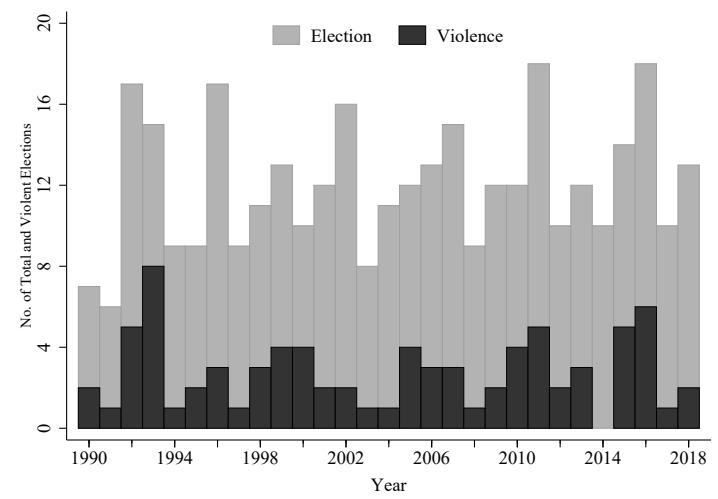

Note: The light gray histogram represents the total number of elections across Sub-Saharan Africa in a given year. The black histogram overlaid on the gray, is representative of the total number of elections which encountered violence. Calendar year is represented on the $\mathrm{x}$-axis, and the $\mathrm{y}$-axis shows the number of total and violent elections. The figure highlights the frequency of elections in Africa that were associated with violent episodes at any time (Panel A) and after the election period (Panel B) within the calendar year corresponding to the election. Data on elections with and without violence were compiled and calculated from the universe of all country-specific Human Rights Reports published by the U.S. Department of State. Data Appendix D provides additional details. 


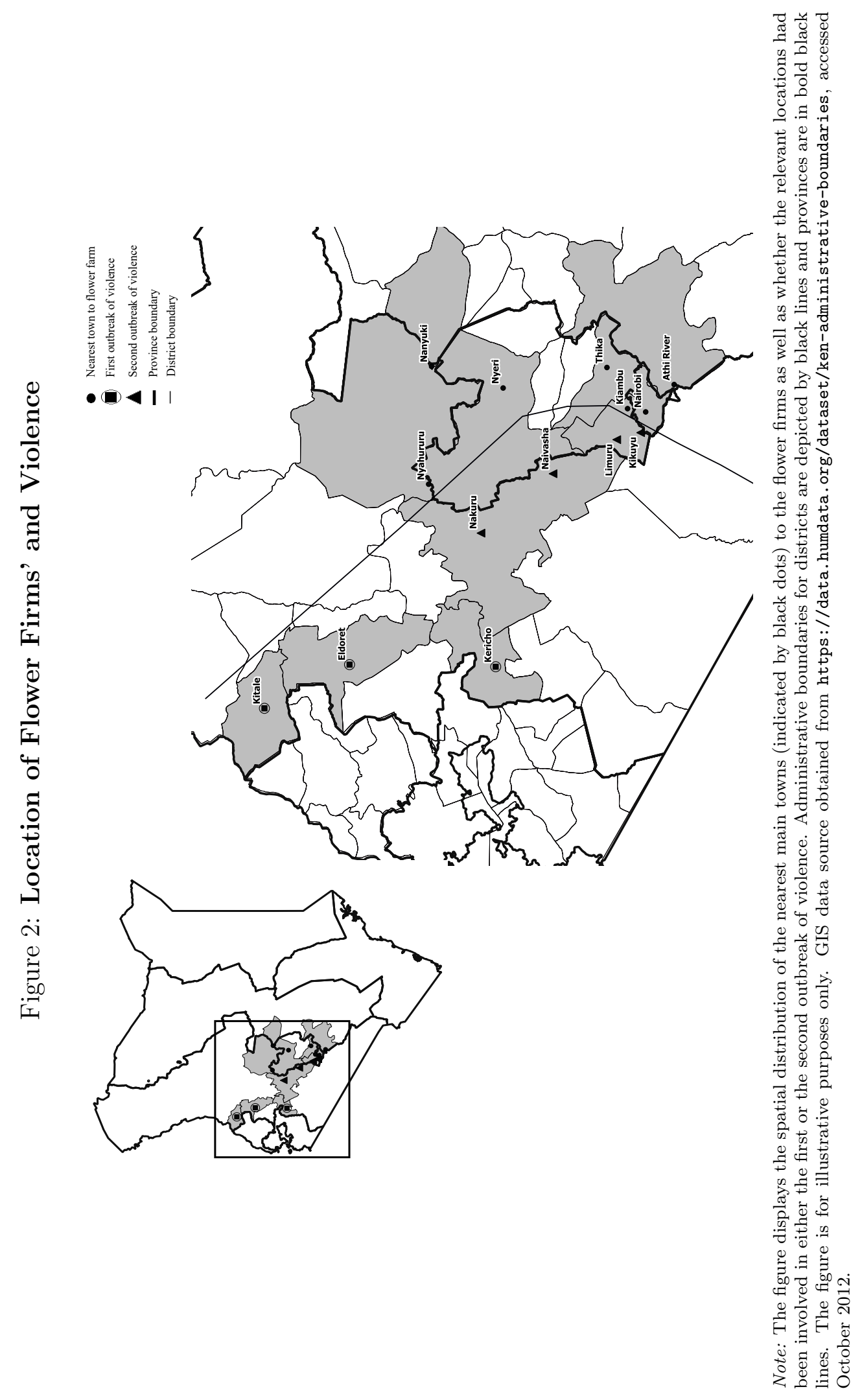




\section{Figure 3: Effect of Violence on Export Volumes, Short-Run}

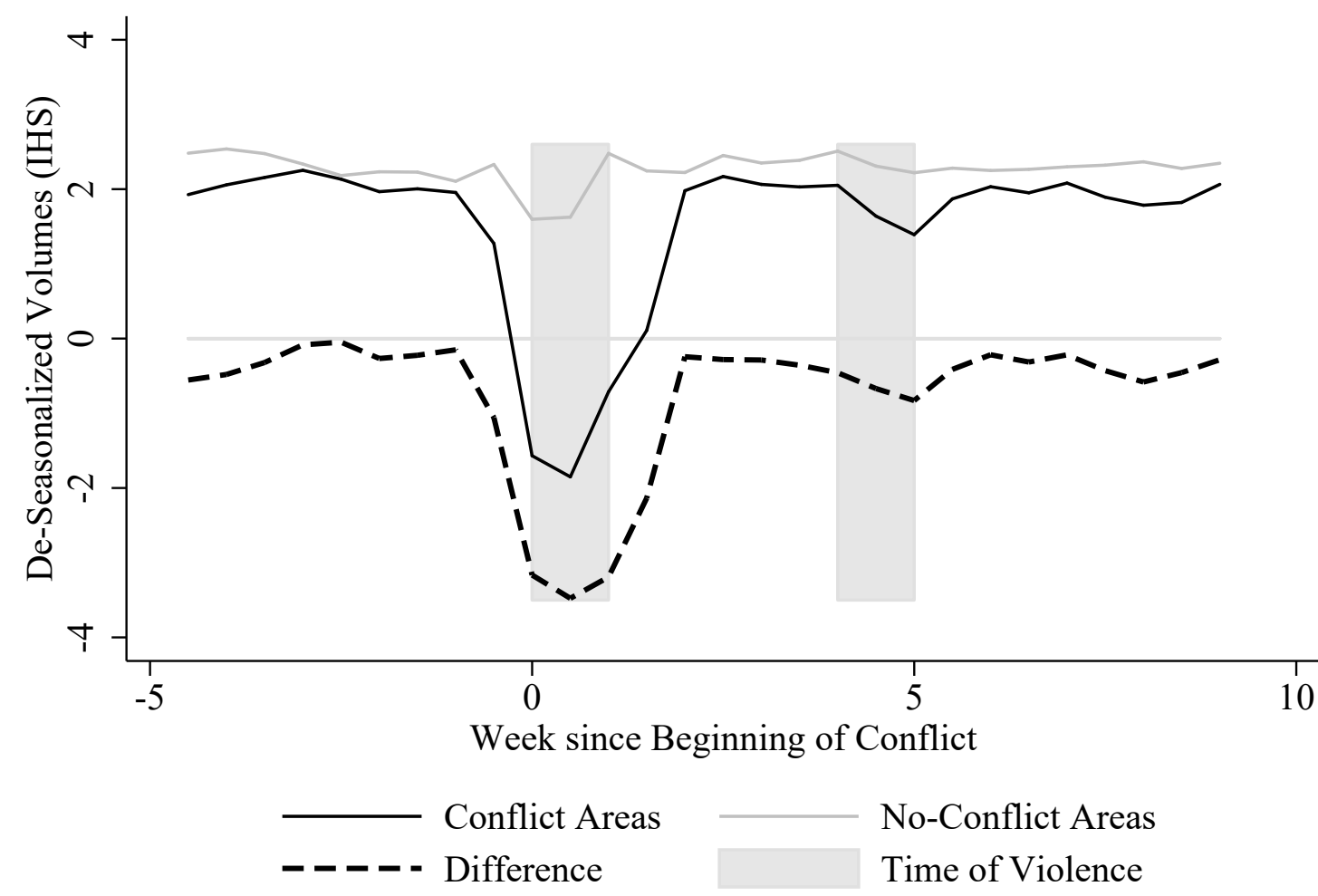

Note: The figure displays the smoothed median biweekly residuals from a regression of export weights (kgs, inverse hyperbolic sine transformation) on the following fixed effects: firm, day of week, and day of year and winter with violence location, and presenting residuals separately for the conflict and no-conflict areas (Table [3, column 4). Smoothing is through simple moving average. The shaded area indicates times of violence. Conflict areas are as defined as in Appendix Table C1. 


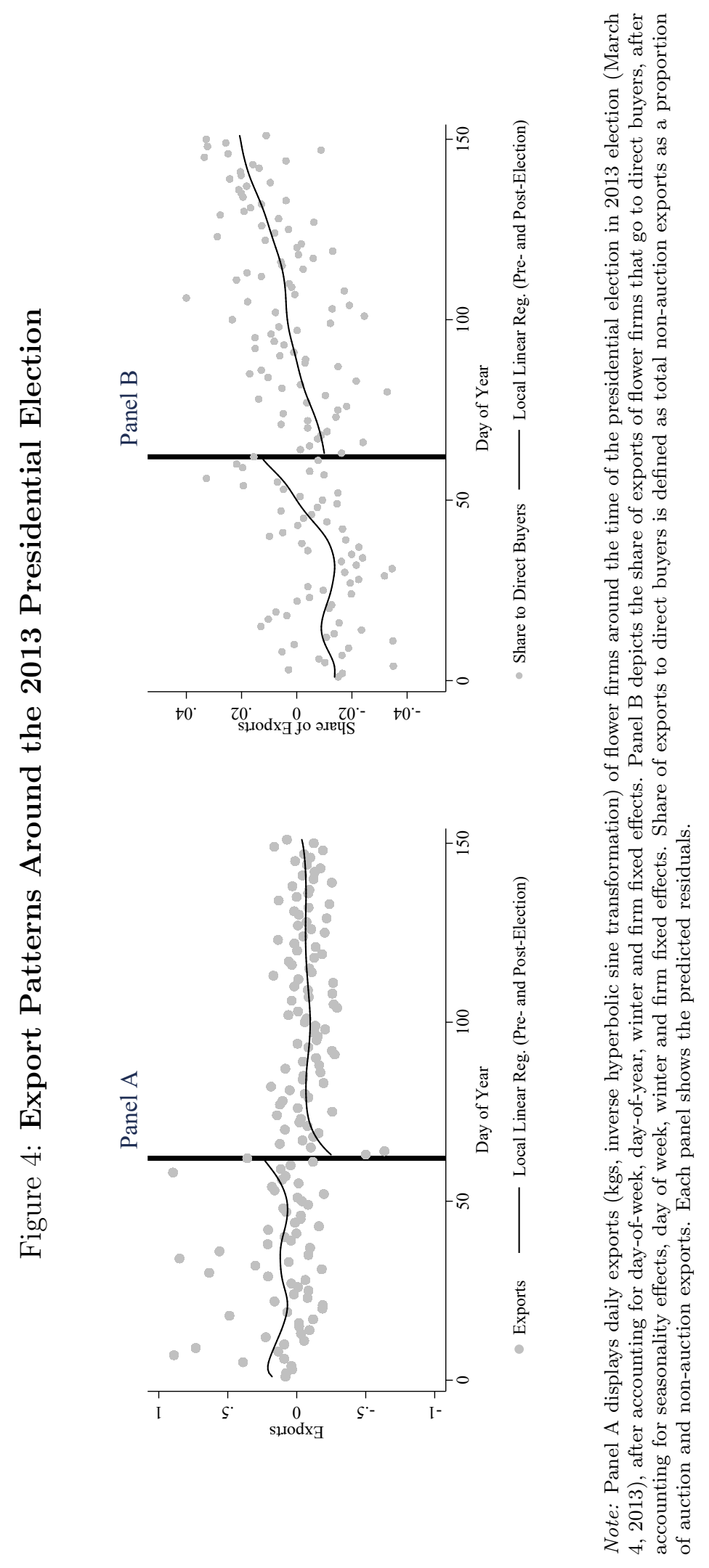




\section{Table 1: Descriptive Statistics}

\begin{tabular}{|c|c|c|c|c|c|}
\hline \multicolumn{6}{|c|}{ Panel A: Firms in Areas with and without Violence, Administrative Records } \\
\hline \multirow[b]{2}{*}{ Variable } & \multicolumn{2}{|c|}{ No violence } & \multicolumn{2}{|c|}{ Violence } & \multirow[b]{2}{*}{$\mathrm{P}$-value } \\
\hline & Mean & $\mathrm{SE}$ & Mean & $\mathrm{SE}$ & \\
\hline Export, Jan-Feb 2007 (kg '000) & 11.54 & $(0.20)$ & 10.95 & $(0.28)$ & 0.10 \\
\hline Small & 0.42 & $(0.07)$ & 0.47 & $(0.06)$ & 0.64 \\
\hline Foreign Owner & 0.32 & $(0.06)$ & 0.42 & $(0.06)$ & 0.22 \\
\hline Indian Owner & 0.21 & $(0.05)$ & 0.21 & $(0.05)$ & 0.98 \\
\hline Kenyan Owner & 0.40 & $(0.07)$ & 0.30 & $(0.06)$ & 0.25 \\
\hline Politically Connected Firm & 0.28 & $(0.06)$ & 0.15 & $(0.04)$ & $0.08^{*}$ \\
\hline Exports to Auctions & 0.40 & $(0.07)$ & 0.26 & $(0.06)$ & $0.10^{*}$ \\
\hline Production in Roses & 0.56 & $(0.07)$ & 0.53 & $(0.06)$ & 0.79 \\
\hline \multicolumn{6}{|c|}{ Panel B: Firms in Areas with and without Violence, Survey Data } \\
\hline & \multicolumn{2}{|c|}{ No violence } & \multicolumn{2}{|c|}{ Violence } & \\
\hline Variable & Mean & $\mathrm{SE}$ & Mean & $\mathrm{SE}$ & $\mathrm{P}$-value \\
\hline Number of Workers Jan 2008 & 521.89 & $(112.59)$ & 441.13 & $(45.34)$ & 0.44 \\
\hline Female Workers $(\%)$ & 61.42 & $(2.18)$ & 64.39 & $(2.68)$ & 0.42 \\
\hline Temporary Workers (\%) & 18.56 & $(4.98)$ & 23.78 & $(4.37)$ & 0.45 \\
\hline Workers with Primary Education (\%) & 90.40 & $(1.57)$ & 91.21 & $(1.46)$ & 0.71 \\
\hline Workers Housed & 0.48 & $(0.10)$ & 0.30 & $(0.07)$ & 0.13 \\
\hline Entry Year & 1997 & $(1.06)$ & 1999 & $(0.72)$ & $0.03^{* *}$ \\
\hline Association Member & 0.67 & $(0.09)$ & 0.49 & $(0.08)$ & 0.15 \\
\hline Certification & 0.81 & $(0.08)$ & 0.69 & $(0.07)$ & 0.25 \\
\hline Number of Insulated Trucks & 1.42 & $(0.24)$ & 1.05 & $(0.24)$ & 0.29 \\
\hline Sold to Direct Buyers (\%) & 50.36 & $(8.73)$ & 38.54 & $(6.73)$ & 0.28 \\
\hline Workers at Risk (\%) & 12.38 & $(2.73)$ & 32.57 & $(4.89)$ & $0.00^{* * *}$ \\
\hline Affected Operations & 0.37 & $(0.09)$ & 0.87 & $(0.05)$ & $0.00^{* * *}$ \\
\hline Experienced Worker Absence & 0.23 & $(0.08)$ & 0.87 & $(0.05)$ & $0.00^{* * *}$ \\
\hline Workers Lost (\%) & 4.15 & $(2.72)$ & 49.33 & $(5.75)$ & $0.00^{* * *}$ \\
\hline Production Loss because of Worker Absence & 0.26 & $(0.17)$ & 2.35 & $(0.20)$ & $0.00^{* * *}$ \\
\hline Transportation Problems & 0.26 & $(0.09)$ & 0.64 & $(0.07)$ & $0.00^{* * *}$ \\
\hline Hire Extra Security & 0.08 & $(0.06)$ & 0.38 & $(0.08)$ & $0.01^{* * *}$ \\
\hline \multicolumn{6}{|c|}{ Panel C: Surveyed vs. Non-Surveyed Firms, Administrative Records } \\
\hline \multirow[b]{2}{*}{ Variable } & \multicolumn{2}{|c|}{ No violence } & \multicolumn{2}{|c|}{ Violence } & \\
\hline & Mean & $\mathrm{SE}$ & Mean & $\mathrm{SE}$ & P-value \\
\hline Export, Jan-Feb 2007, in kg '000 & 10.82 & $(0.31)$ & 11.50 & $(0.21)$ & $0.06^{*}$ \\
\hline Violence Region & 0.40 & $(0.07)$ & 0.63 & $(0.06)$ & $0.01^{* *}$ \\
\hline Small & 0.51 & $(0.07)$ & 0.40 & $(0.06)$ & 0.26 \\
\hline Foreign Owner & 0.34 & $(0.07)$ & 0.40 & $(0.06)$ & 0.52 \\
\hline Indian Owner & 0.20 & $(0.06)$ & 0.22 & $(0.05)$ & 0.80 \\
\hline Kenyan Owner & 0.34 & $(0.07)$ & 0.36 & $(0.06)$ & 0.85 \\
\hline Politically Connected Firm & 0.20 & $(0.06)$ & 0.22 & $(0.05)$ & 0.80 \\
\hline Exports to Auctions & 0.38 & $(0.07)$ & 0.28 & $(0.06)$ & 0.27 \\
\hline Production in Roses & 0.45 & $(0.07)$ & 0.61 & $(0.06)$ & $0.08^{*}$ \\
\hline
\end{tabular}

Note: $* * *, * *, *$ denote statistical significance at the 1,5 and 10 percent levels, respectively. Panel A tests differences in samplemeans for firms in the regions affected by the violence and firms in regions unaffected by the violence using administrative records only. The sample of firms is the universe of established exporters active in the industry at the time of the violence, after excluding the four largest firms, traders and infrequent exporters. Exports in the first two months of 2007 (in '000 kgs), Production in Roses and Exports to Auctions are computed from official trade statistics. Small, firm ownership (Foreign, Indian and Kenyan) and Politically Connected Firm are all dummy variables. Information on the source of firm ownership and political connectedness is detailed in the Data Appendix D Panel B tests differences in sample-means for firms in the locations affected by the violence and firms in locations unaffected by the violence using information collected through a face-to-face survey designed and conducted by the authors. Workers Housed is a dummy variable taking a value of 1 if the firm offers housing for workers at the premises and 0 otherwise. Entry Year is the year in which the firm starts to export flowers. Association Member is a dummy variable taking a value of 1 if the firm is a member of the Kenya Flower Council (KFC) and 0 otherwise. Certification is a dummy variable taking a value of 1 if the firm is a participant in any of the standard certification programs during our study period (Fair-Trade, Max Havelaar Switzerland, Milieu Programma Sierteelt (MPS), and Kenya Flower Certification). Workers at Risk is percentage of the workforce that is at risk of violence. We define being at risk as being a member of an ethnic group that was in the opposite alliance from the majority ethnic group of the location from Population Census data. Affected Operations, Experienced Worker Absence, Transportation Problems and Hire Extra Security are all dummy variables capturing margins of firm disruptions due to electoral violence. Production Loss because of Worker Absence is a categorical variable taking values from 0 (not at all) to 4 (severe). Panel $\mathrm{C}$ shows that surveyed and non-surveyed firms do not differ for the administrative data available for both samples. Violence Region is a dummy taking a value of 1 if the firm is an locality where electoral violence took place, 0 otherwise. Additional details on data construction and data source are provided in the Data Appendix D 


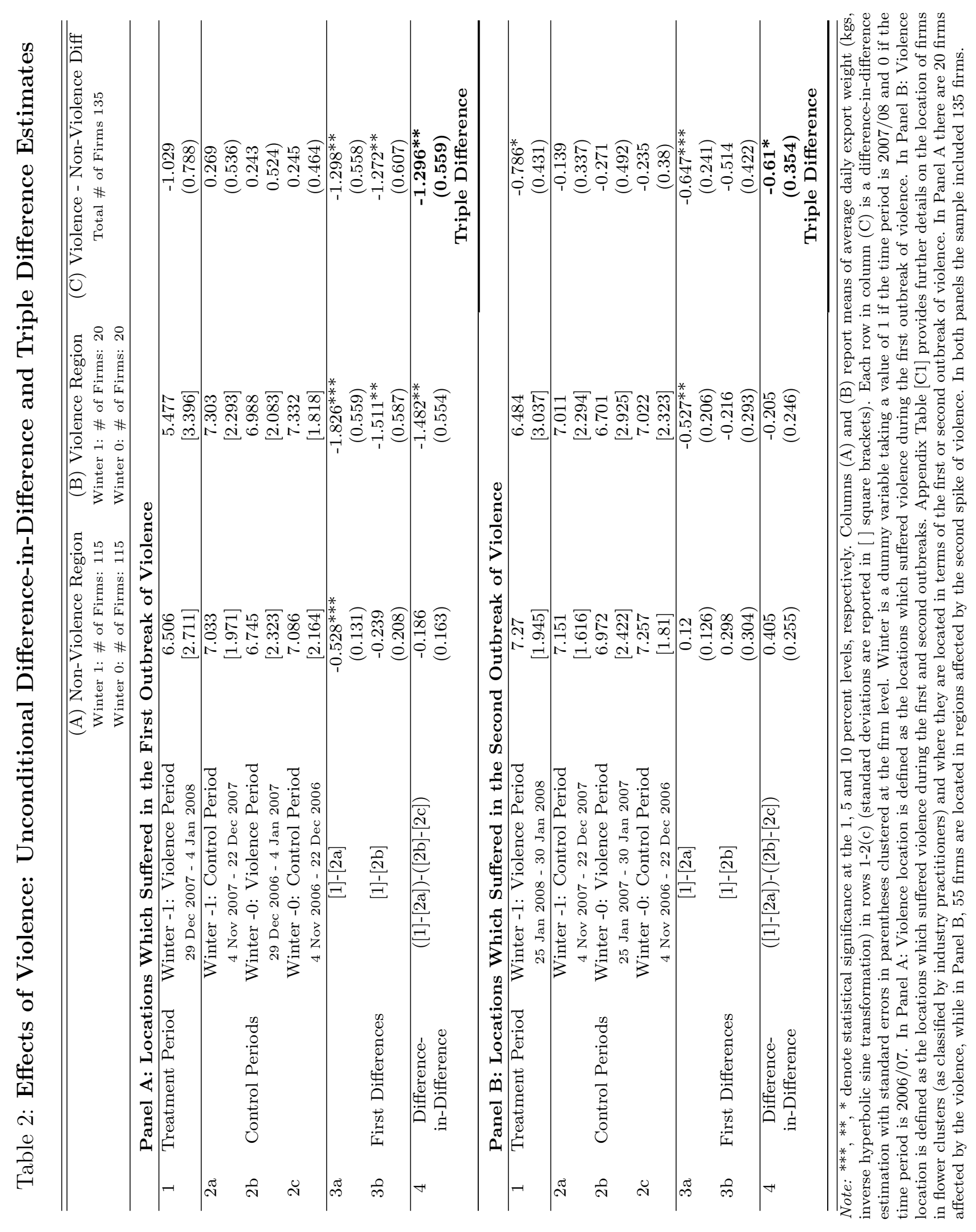




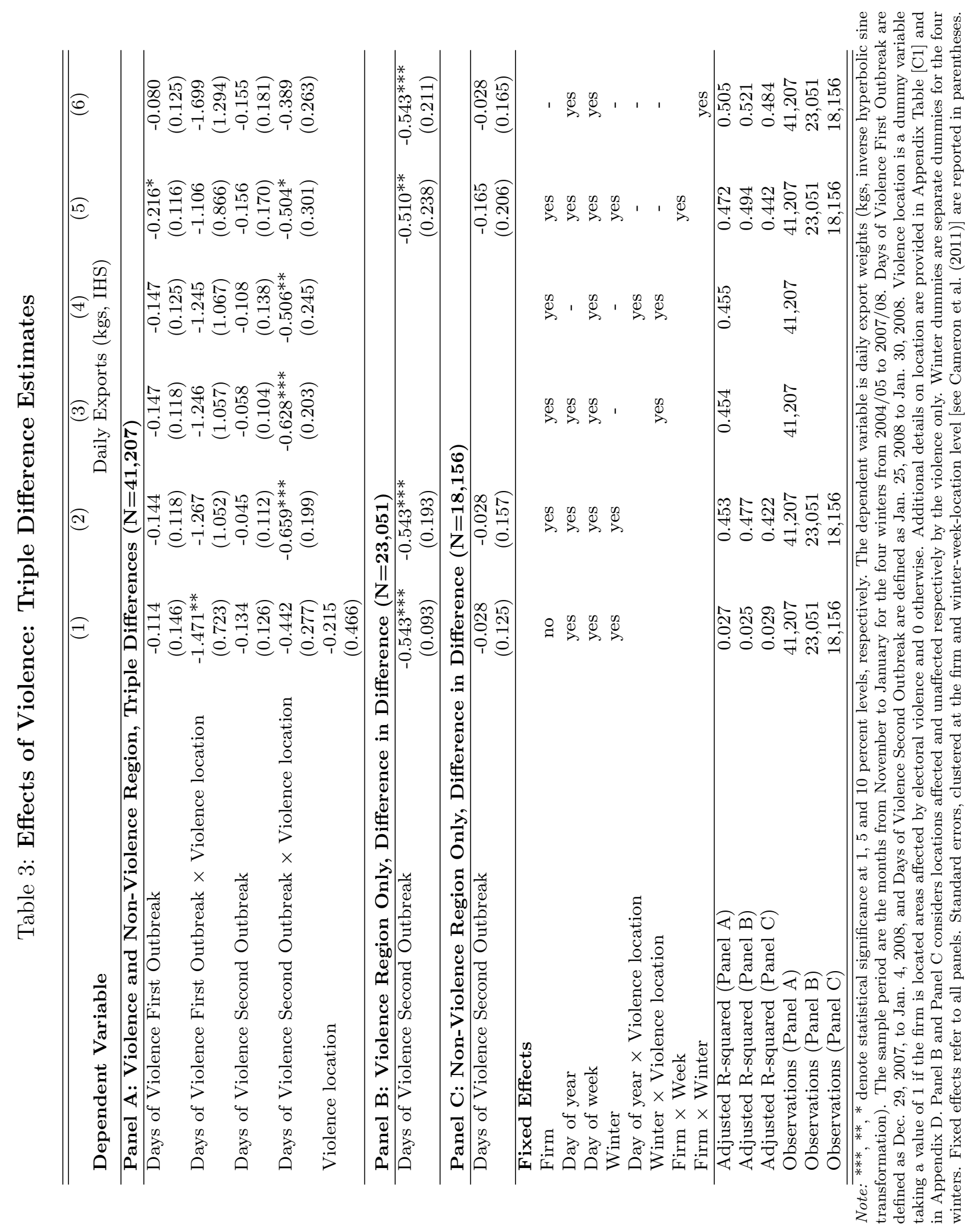




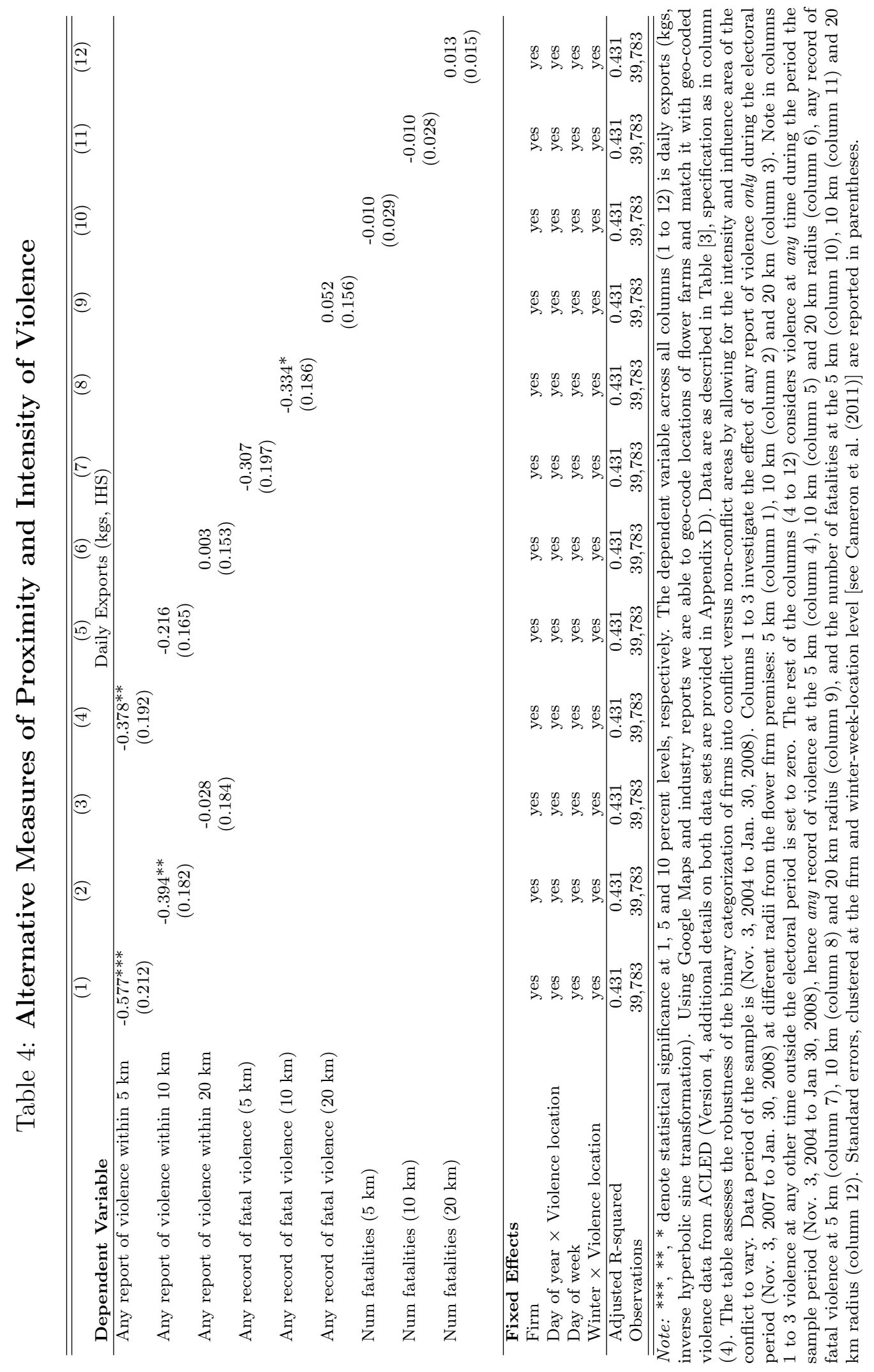




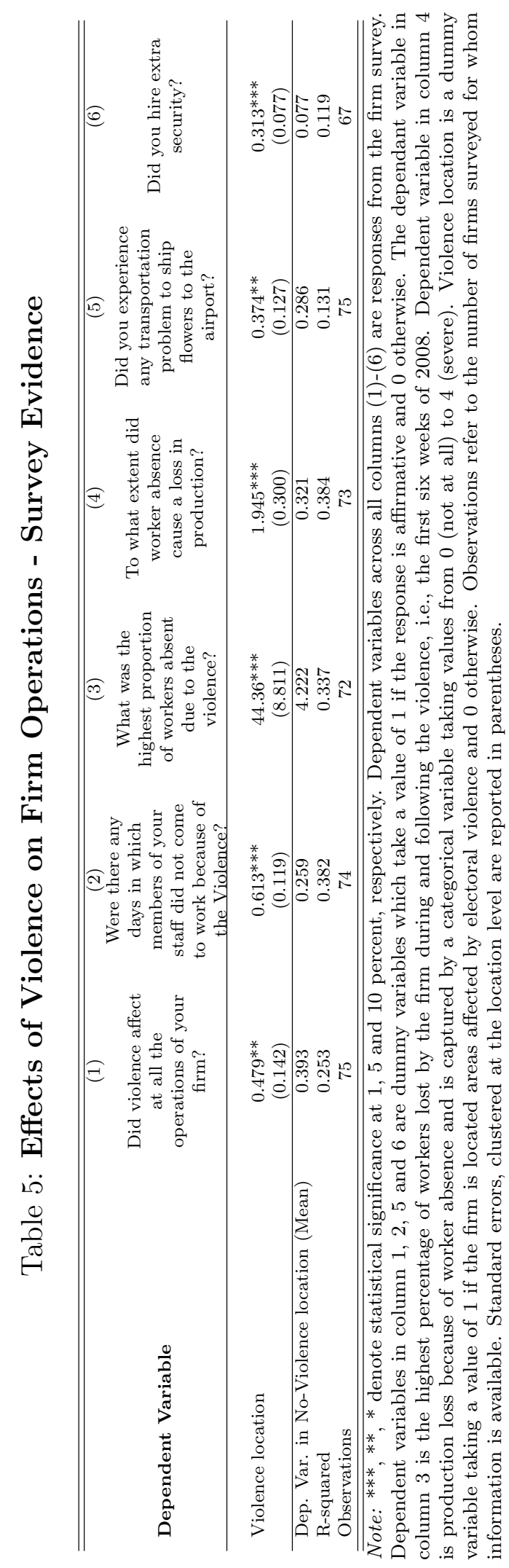




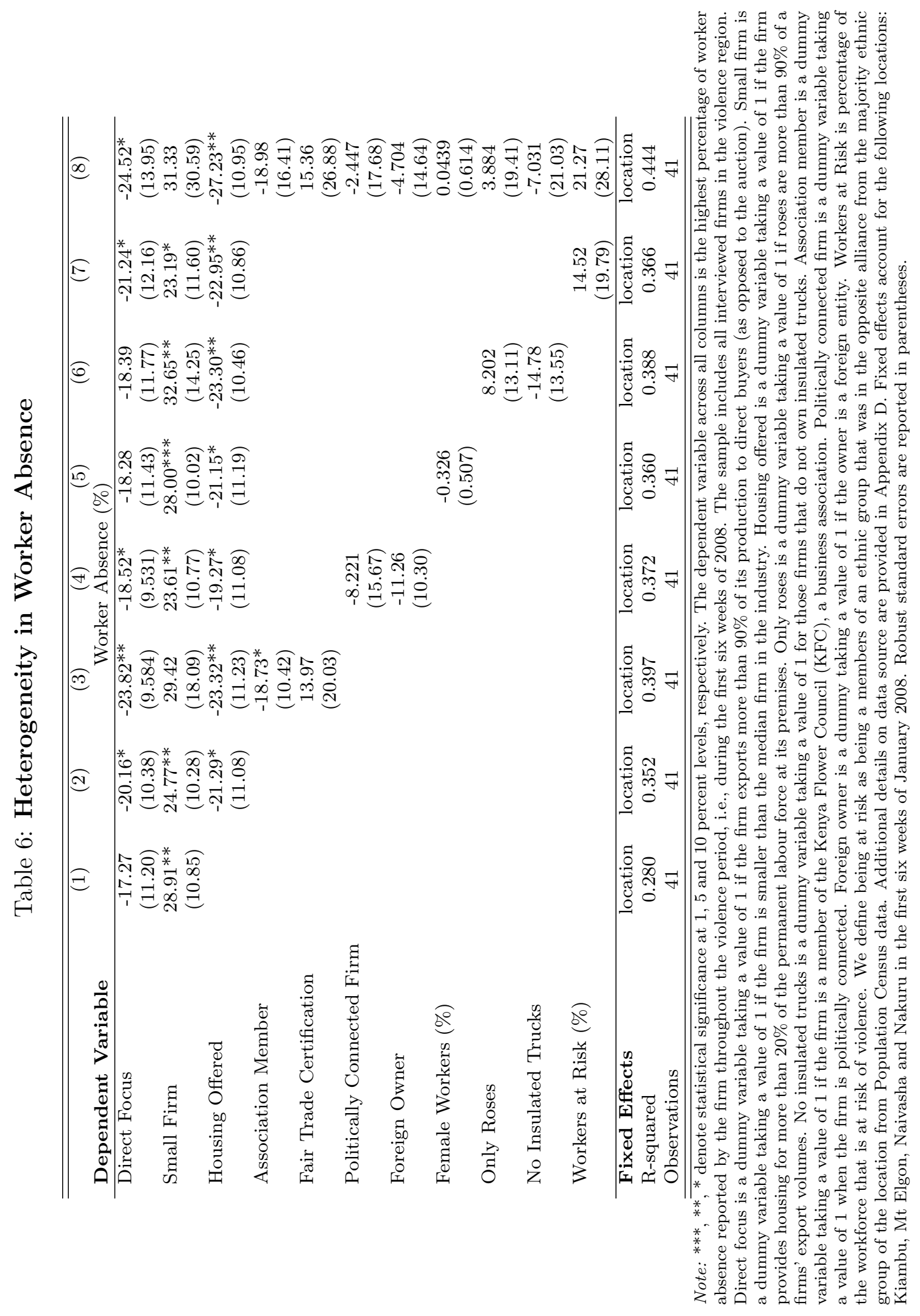




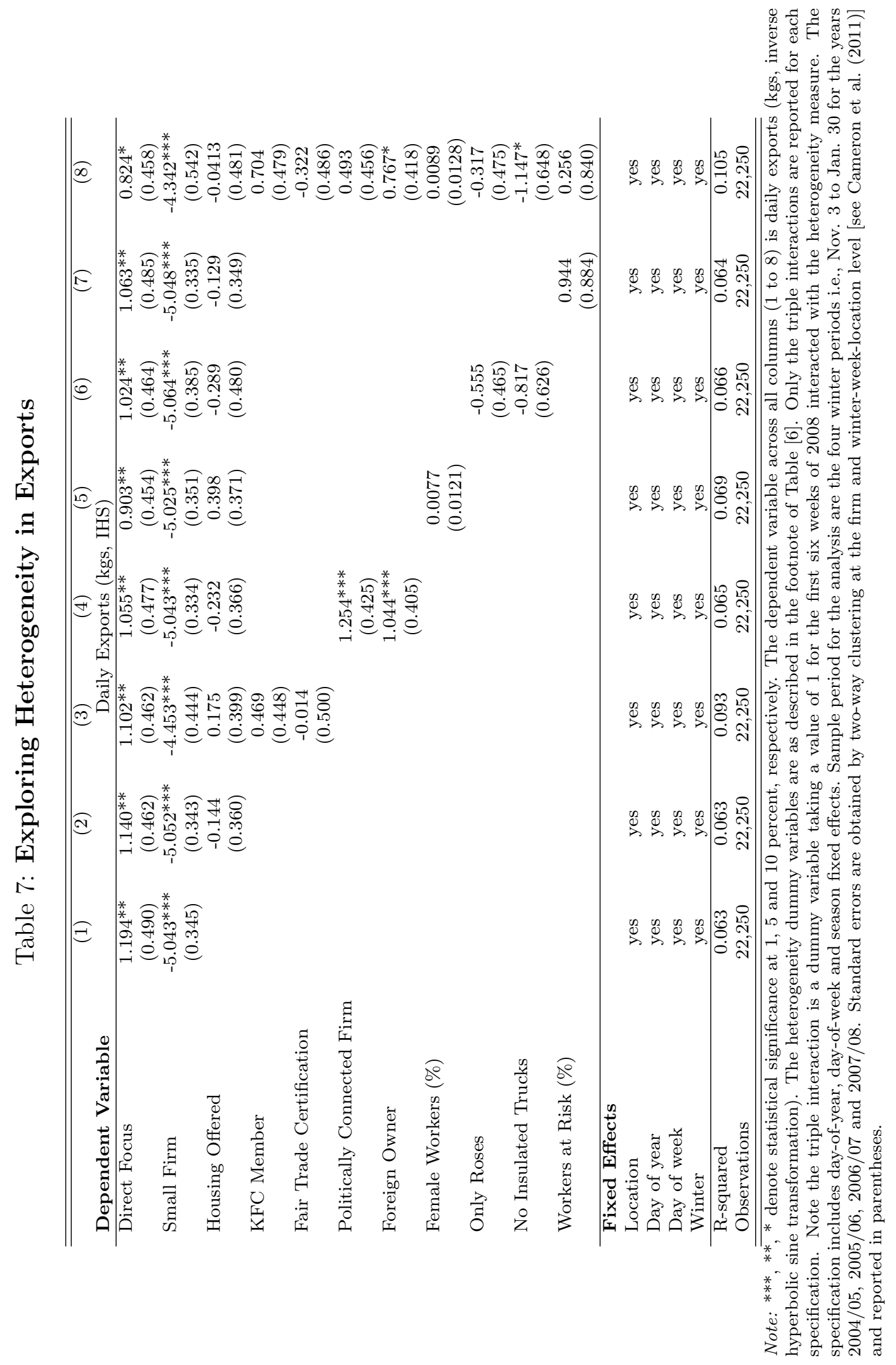




\section{Table 8: Buyer-Driven Spillovers Across Regions within Kenya}

\begin{tabular}{|c|c|c|c|c|}
\hline \multirow[b]{2}{*}{ Dependent Variable } & $(1)$ & $(2)$ & $(3)$ & $(4)$ \\
\hline & \multicolumn{4}{|c|}{ Total Daily Exports (kgs, IHS) in Firm-Buyer pair } \\
\hline Days of Violence & $\begin{array}{l}-0.037 \\
(0.058)\end{array}$ & $\begin{array}{l}-0.037 \\
(0.043)\end{array}$ & $\begin{array}{l}-0.012 \\
(0.055)\end{array}$ & $\begin{array}{l}-0.012 \\
(0.045)\end{array}$ \\
\hline $\begin{array}{l}\text { Days of Violence } \times \text { Proportion Purchased from Violence Location } \\
\text { in the Months Preceding Violence }\end{array}$ & $\begin{array}{c}0.066 \\
(0.174)\end{array}$ & $\begin{array}{c}0.066 \\
(0.131)\end{array}$ & & \\
\hline $\begin{array}{l}\text { Days of Violence } \times \text { Any Purchase from Violence Location } \\
\text { in the Months Preceding Violence }\end{array}$ & & & $\begin{array}{l}-0.012 \\
(0.081)\end{array}$ & $\begin{array}{l}-0.012 \\
(0.067)\end{array}$ \\
\hline \multicolumn{5}{|l|}{ Fixed Effects } \\
\hline Buyer & yes & no & yes & no \\
\hline Firm - Buyer & no & yes & no & yes \\
\hline Day of year & yes & yes & yes & yes \\
\hline Day of week & yes & yes & yes & yes \\
\hline Winter & yes & yes & yes & yes \\
\hline Adjusted R-squared & 0.094 & 0.305 & 0.094 & 0.305 \\
\hline Observations & 218,811 & 218,811 & 218,811 & 218,811 \\
\hline
\end{tabular}

Note: ***,**,* denote statistical significance at 1, 5 and 10 percent, respectively. The dependent variable across all columns (1 to 4 ) is total daily exports (kgs, inverse hyperbolic sine transformation) in a firm-buyer relationship. Days of violence is a dummy variable taking a value of 1 if the date in the sample is between and including Dec. 29,2007 to Jan. 4, 2008 and Jan. 25, 2008 to Jan. 30, 2008; and 0 otherwise. Proportion purchased from violence location in the months preceding violence, is the proportion of flower purchases the buyer of this exporter-buyer pair (i.e. a direct relationship) made from a violence location as a proportion of all of the buyer's purchases in the months prior to the occurrence of violence. Any purchase from violence location in the months preceding violence, is a dummy variable which takes the value of 1 if there are any purchases the buyer in this exporter-buyer pair (i.e. direct relationship) made from any exporter located in a violence location. Violence location are locations which suffered violence during the first or second outbreaks. Appendix Table C1 provides further details on the location of firms in flower clusters (as classified by industry practitioners) and where they are located in terms of the first or second outbreak of violence. Preceding violence refers to the period Nov. 1, 2007 to Dec. 21, 2007. Sample period for the analysis is Nov. 3 to Jan. 30 for the years 2004 to 2010, i.e. six winters. Standard errors are obtained by two-way clustering [see Cameron et al. (2011)] at buyer and season-week level (columns 1 and 3) and buyer-firm relationship and season-week level (columns 2 and 4 ) and reported in parentheses. 
Table 9: Buyer-Driven Spillovers into Ethiopia

\begin{tabular}{|c|c|c|c|c|c|}
\hline \multirow[b]{2}{*}{ Dependent Variable } & (1) & $(2)$ & $(3)$ & \multirow{2}{*}{$\begin{array}{l}(4) \\
\text { in Firm }\end{array}$} & \multirow{2}{*}{$\begin{array}{c}(5) \\
\text { Buyer pair }\end{array}$} \\
\hline & Total Da & ily Expor & s (kgs, IHS & & \\
\hline Days of Violence & $\begin{array}{l}-0.080 \\
(0.059)\end{array}$ & $\begin{array}{l}-0.082 \\
(0.062)\end{array}$ & $\begin{array}{l}-0.082 \\
(0.062)\end{array}$ & $\begin{array}{l}-0.082 \\
(0.062)\end{array}$ & $\begin{array}{l}-0.082 \\
(0.062)\end{array}$ \\
\hline $\begin{array}{l}\text { Days of Violence } \times \text { Proportion Purchased from Violence Location } \\
\text { in the Months Preceding Violence }\end{array}$ & & $\begin{array}{l}-0.684 \\
(0.593)\end{array}$ & & & \\
\hline $\begin{array}{l}\text { Days of Violence } \times \text { Any Flowers Purchased from Violence Location } \\
\text { in the Months Preceding Violence }\end{array}$ & & & $\begin{array}{r}-0.397^{*} \\
(0.212)\end{array}$ & & \\
\hline $\begin{array}{l}\text { Days of Violence } \times \text { Proportion Purchased from Kenya } \\
\text { in the Months Preceding Violence }\end{array}$ & & & & $\begin{array}{c}0.386 \\
(0.379)\end{array}$ & \\
\hline $\begin{array}{l}\text { Days of Violence } \times \text { Any Flowers Purchased from Kenya } \\
\text { in the Months Preceding Violence }\end{array}$ & & & & & $\begin{array}{c}0.084 \\
(0.253) \\
\end{array}$ \\
\hline Fixed Effects & & & & & \\
\hline Firm & yes & - & - & - & - \\
\hline Firm - Buyer & - & yes & yes & yes & yes \\
\hline Day of year & yes & yes & yes & yes & yes \\
\hline Day of week & yes & yes & yes & yes & yes \\
\hline Winter & yes & yes & yes & yes & yes \\
\hline Adjusted R-squared & 0.199 & 0.360 & 0.360 & 0.360 & 0.360 \\
\hline Observations & 90,478 & 83,997 & 83,997 & 83,997 & 83,997 \\
\hline
\end{tabular}

Note: ${ }^{* * *},{ }^{* *},{ }^{*}$ denote statistical significance at 1,5 and 10 percent, respectively. The dependent variable across all columns ( 1 to 4 ) is total daily exports (kgs, inverse hyperbolic sine transformation) in a firm-buyer relationship. Days of violence is dummy variable taking a value of 1 if the date in the sample is between and including Dec. 29, 2007 to Jan. 4, 2008 and Jan. 25, 2008 to Jan. 30, 2008. Proportion purchased from violence location in the months preceding violence, is the proportion of flower purchases the buyer of this exporter-buyer pair (i.e. a direct relationship) made from a violence location in Kenya as a proportion of the buyer's purchases from either Kenya or Ethiopia in the months prior to the occurrence of violence. Any purchase from violence location in the months preceding violence, is a dummy variable which takes the value of 1 if this proportion is bigger than zero. The two variables Proportion purchased from Kenya and any flowers purchased from Kenya are defined in the same manner, except with reference to exports from Kenya as a whole. Violence location are locations which suffered violence during the first and second outbreaks. Appendix Table C1] provides further details on the location of firms in flower clusters (as classified by industry practitioners) and where they are located in terms of the first or second outbreak of violence. Preceding violence refers to Nov. 1, 2007 to Dec. 21, 2007. Sample period for the analysis is Nov. 1 to Mar. 9 for the years 2007 to 2010, i.e. three winters, so that seasonality patterns are estimated with post-violence data. Standard errors obtained through clustering at firm-level (column 1) and firm-buyer relationship level (columns 2-5) and reported in parentheses. 


\section{Table 10: Anticipation Effects in the 2013 Election}

\begin{tabular}{|c|c|c|c|c|c|c|}
\hline Dependent Variable & $\begin{array}{c}(1) \\
\text { Daily } \\
\text { Exports } \\
(\mathrm{kgs}, \mathrm{IHS})\end{array}$ & $\begin{array}{c}(2) \\
\text { Share to } \\
\text { Direct } \\
\text { Buyers } \\
\end{array}$ & $\begin{array}{c}(3) \\
\text { Daily } \\
\text { Exports } \\
\text { (kgs, IHS) }\end{array}$ & $\begin{array}{c}(4) \\
\text { Share to } \\
\text { Direct } \\
\text { Buyers }\end{array}$ & $\begin{array}{c}(5) \\
\text { Daily } \\
\text { Exports } \\
\text { (kgs, IHS) }\end{array}$ & $\begin{array}{c}(6) \\
\text { Share to } \\
\text { Direct } \\
\text { Buyers }\end{array}$ \\
\hline Days before the 2013 election & $\begin{array}{c}0.168^{* *} \\
(0.070)\end{array}$ & $\begin{array}{c}0.032^{* * *} \\
(0.010)\end{array}$ & & & $\begin{array}{c}0.319^{* * *} \\
(0.072)\end{array}$ & $\begin{array}{c}0.015^{*} \\
(0.009)\end{array}$ \\
\hline Days after the 2013 election & & & $\begin{array}{c}-0.208^{* * *} \\
(0.074)\end{array}$ & $\begin{array}{c}-0.027^{* *} \\
(0.010)\end{array}$ & $\begin{array}{c}-0.307^{* * *} \\
(0.069)\end{array}$ & $\begin{array}{l}-0.015^{*} \\
(0.009)\end{array}$ \\
\hline \multicolumn{7}{|l|}{ Fixed Effects } \\
\hline Firm & yes & yes & yes & yes & yes & yes \\
\hline Day of year & yes & yes & yes & yes & yes & yes \\
\hline Day of week & yes & yes & yes & yes & yes & yes \\
\hline Winter & yes & yes & yes & yes & yes & yes \\
\hline Adjusted R-squared & 0.604 & 0.777 & 0.634 & 0.772 & 0.616 & 0.770 \\
\hline Observations & 46,314 & 18,237 & 66,732 & 26,478 & 113,046 & 44,715 \\
\hline
\end{tabular}

Note: $* * *,{ }^{*},{ }^{*}$ denote statistical significance at 1,5 , and 10 percent, respectively. The dependent variable in columns 1,3 and 5 is daily exports (kgs, inverse hyperbolic sine transformation) and in columns 2, 4 and 6 is the share of exports to direct buyers, defined as total non-auction exports as a proportion of exports to the auction or direct buyers. The 2013 election took place on Mar. 4, 2013. Days before the 2013 election is a dummy variable taking a value of 1 if the date falls between Feb. 24 and Mar. 4, 2013 and 0 otherwise. Days after the 2013 election is a dummy variable taking a value of 1 if the date is including and after Mar. 4 and before Mar. 11, 2013 and 0 otherwise. Sample period in column 1 and 2 are the following periods: Jan. 1-Mar. 3 2011, Jan 1-Mar. 2, 2012 and Jan. 1-Mar. 3, 2013; in column 3 and 4 are the following periods: Mar. 4-May 31, 2011; March 3-May 31, 2012 and Mar. 4-May 31, 2013 and columns 5 and 6 are the days from Jan. 1-May 31 in the years 2011 to 2013. Number of observations reduce from the odd numbered columns to the even numbered columns because the odd numbered columns include zero exports to both auction and non-auction, whereas the even columns are conditional on exporting (since the share to buyers is not defined when no exports were done). Standard errors are clustered at the firm level and reported in parentheses. Additional details are provided in Data Appendix D 


\section{Appendix [18 Pages]}

\section{A Model Extension: Transportation Problems}

We now turn to the second mechanism through which the ethnic violence has affected firms' operation: transportation problems. The model is modified as follows. In order to export in any given day, firms face a fixed cost of transportation $T{ }^{45}$ Firms can, however, store flowers for some days. If a flower is stored for $d$ days, it reaches the final market in good condition with probability $\delta^{d / 2}$. Given the data in our sample, we focus on the case in which firms must ship at least once a week - i.e., after $D=6$ days, flowers are worthless.

In normal times, the firm chooses the optimal frequency of shipment, and then adjusts its labor inputs accordingly. The firm's profits when harvesting flowers that are sent after $d$ day, are $\delta^{d} \Pi^{*}$, where $\Pi^{*}$, derived in the main text, now incorporates the transportation costs $T d$. It is easy to show the following:

\section{Lemma}

During normal times, the firm ships every day of the week if $\frac{1-\delta}{T} \Pi^{*} \geq 1$. The firm ships $n \in\{2,3,4\}$ times per week if $\frac{1}{(1+\delta)^{4-n}} \geq \frac{1-\delta}{T} \Pi^{*} \geq \frac{1}{(1+\delta)^{5-n}}$. Otherwise the firm ships once per week.

Conditional on the number of shipments, the firm tends to equalize the amount of flowers exported in every shipment. For this reason, the firm either exports every day of the week, or four times or less per week. On any particular day $d$, the quantity therefore exported by the firm can be decomposed as

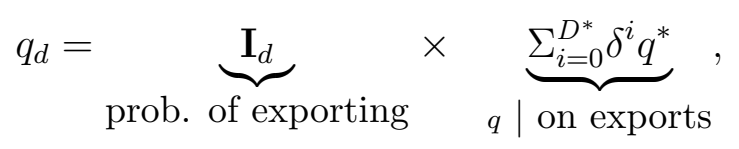

where $\mathbf{I}_{d}=1$ is an indicator of whether the firm exports in day $d$ and $D^{*}$ is the number of days since the previous shipment.

We model the violence as having increased $T$ for a few days. In response, firms readjust $i$ ) their export frequency and $i i$ ) the quantity exported. The effect of the violence

\footnotetext{
${ }^{45}$ The focus on fixed costs, as opposed to variable costs, deserves some justification. The major component of variable transportation costs for the firm are the freight charges. These were not affected by the ethnic violence and, therefore, can be absorbed in the price $p$. Fixed costs in transportation arise, instead, to send one truck to the airport.
} 
on the likelihood of exporting on any given day is negative, since $\frac{1-\delta}{T} \Pi^{*}$ decreases. This implies that, on average, $D^{v}>D^{*}$. The quantity of flowers exported in each shipment, however, might either increase or decrease. The quantity of flowers exported in each shipment decreases if firms do not reduce their export frequency i.e., if $D^{v}=D^{*}$. For these firms, the only effect is $q^{v}<q^{*}$. For firms for which $D^{v}>D^{*}$, however, the quantity of flowers exported in each shipment might increase, since $\sum_{i=0}^{D^{v}} \delta^{i} q^{v} \leq \Sigma_{i=0}^{D^{*}} \delta^{i} q^{*}$. For firms that do not suffer from workers' absence, transportation problems cause i) a decrease in the likelihood of exporting, and ii) conditional on exporting, an increase in the export volumes. 


\section{B Additional Figures}

\section{Figure B1: Timeline of Events}

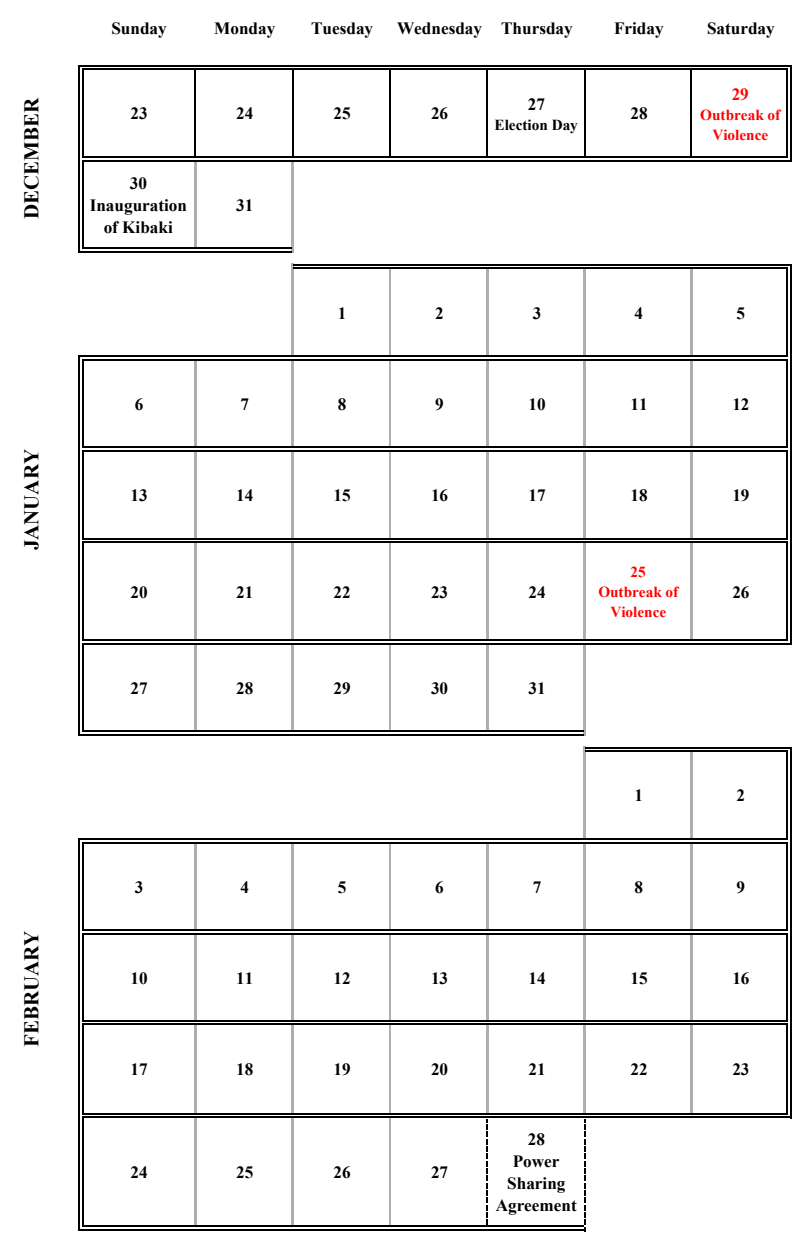

Note: The figure illustrates the timeline of events leading to the two outbreaks of violence in the aftermath of the fourth multi-party general elections in Kenya held on December 27, 2007. The challenger (Odinga, ODM party) led on the first day of counting (December 28, 2007) leading them to declare a initial victory (December 29, 2007). However on December 29, 2007 the head of the Electoral Commission of Kenya declared Kibaki the winner, by a margin of $2 \%$. The hasty inauguration of Kibaki on the afternoon of December 30, 2007 resulted in Odinga accusing the government of fraud. Within minutes of the announcements of the election results, a political and humanitarian crisis erupted nationwide. Targeted ethnic violence broke out in various parts of the country where ODM supporters, targeted Kikuyus who were living outside their traditional settlement areas of the Central province. This first outbreak of violence, which lasted for a few days, was followed by a second outbreak of violence between January 25 and January 30, 2008 when mediation efforts failed. This second phase of violence happened mainly in the areas of Nakuru, Naivasha and Limuru as a revenge attack on members of ethnic groups perceived to be ODM supporters. Sporadic violence and chaos continued until a power-sharing agreement was reached on February 29 , 2008. 


\section{Figure B2: Illustration of Identification Strategy}
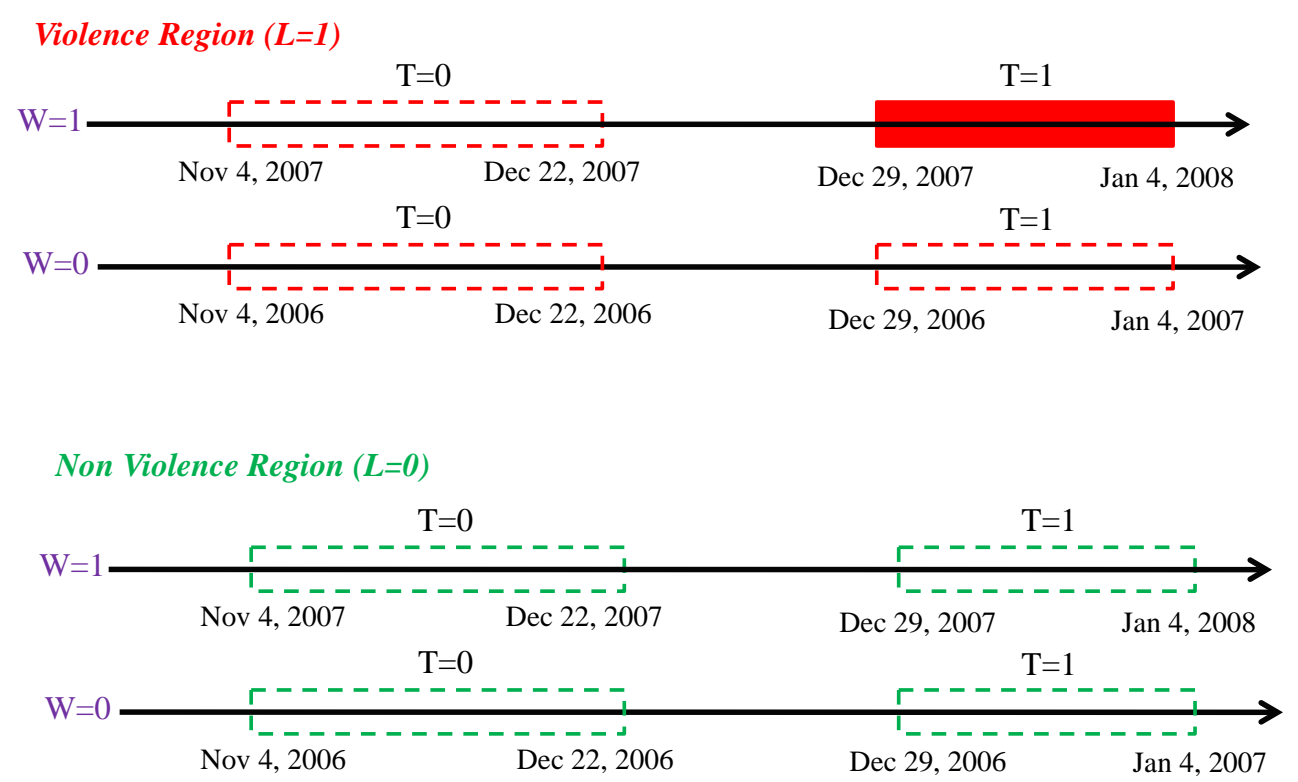

Note: The figure illustrates our identification strategy. In order to estimate the impact of the violence on exports, it is necessary to control for both growth across years and the fact that exports within any year follow a seasonal pattern. Our main dependent variable is daily exports $\left(Y(i)_{T, W}^{L}\right)$, i.e. exports of flowers by firm $i$ located in location $L$ in period $T$ in winter $W$. The indicator $L$ takes a value of $L=1$ if the firm is in a location that is affected by the violence after the election and $L=0$ otherwise. The indicator $T$ takes a value of $T=1$ during the weeks in January 2008 and early February 2008 during which violence occurred and $T=0$ during our control period, which are the 10 weeks before the end of December. Finally, the indicator $W$ takes value equal to $W=1$ in the winter during which the violence occurred - that is the winter of $2007 / 8$ - and $W=0$ for the previous winter. With this notation, a firm was directly affected during a particular spike of violence if and only if $V=L \times T \times W=1$. 


\section{Figure B3: Exports of Traders and Infrequent Exporters}

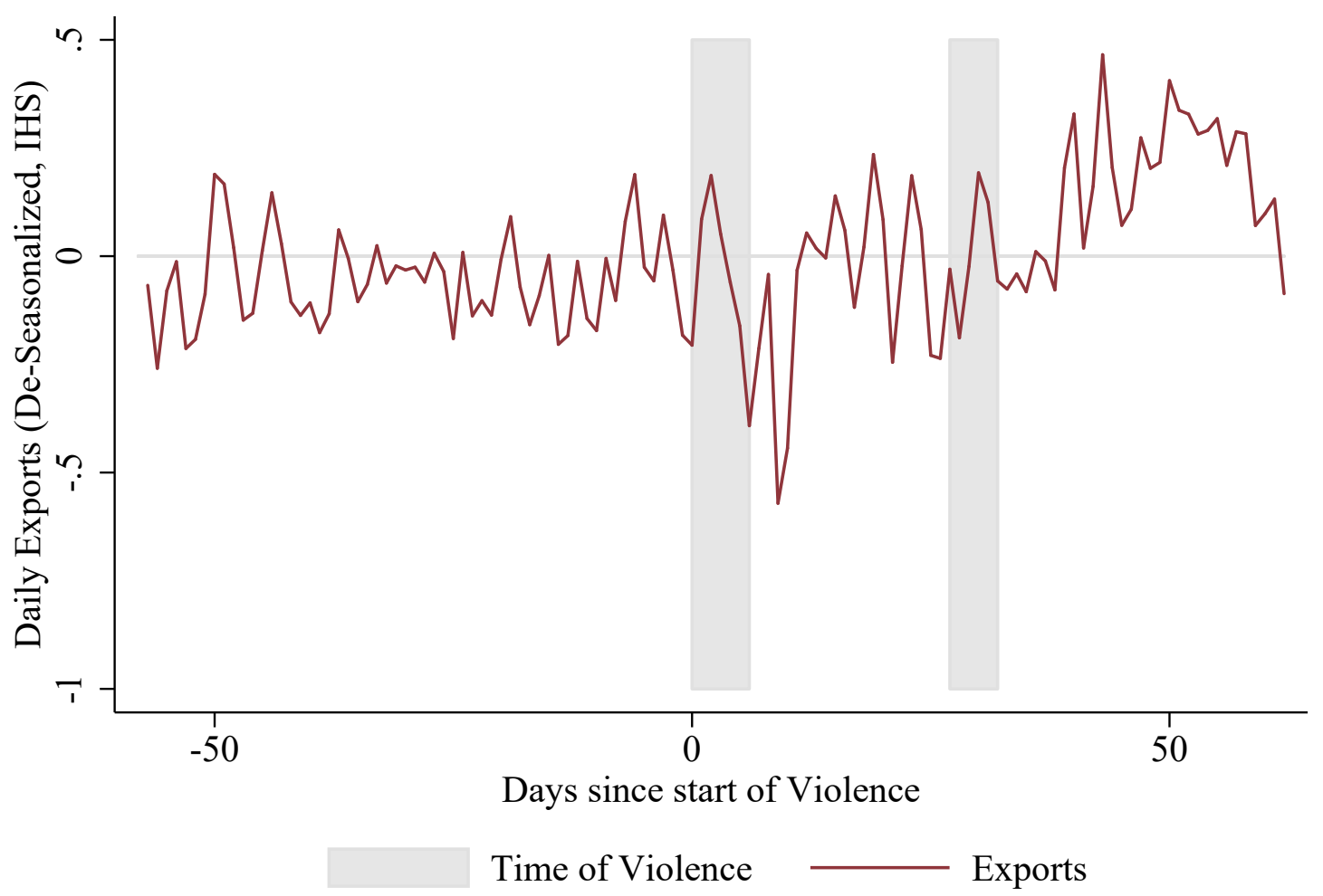

Note: The figure reports the residuals from a regression of the inverse hyperbolic sine transformation of the two-day moving average of exports (kgs) on day of year, day of week and season fixed effects. The exports are aggregated across traders (who do not know own flower farms but instead purchase and export flowers) and infrequent exporters defined as all exporters who are not traders or the regular exporters analyzed in Table 2 and Table 3 around the period of the electoral violence. A two-day moving average is reported as it retains the higher variability during the violence period relative to the period before the violence while providing minimal smoothing of the daily data. 


\section{Figure B4: Effect of Violence on Export Volumes, Medium-Run}

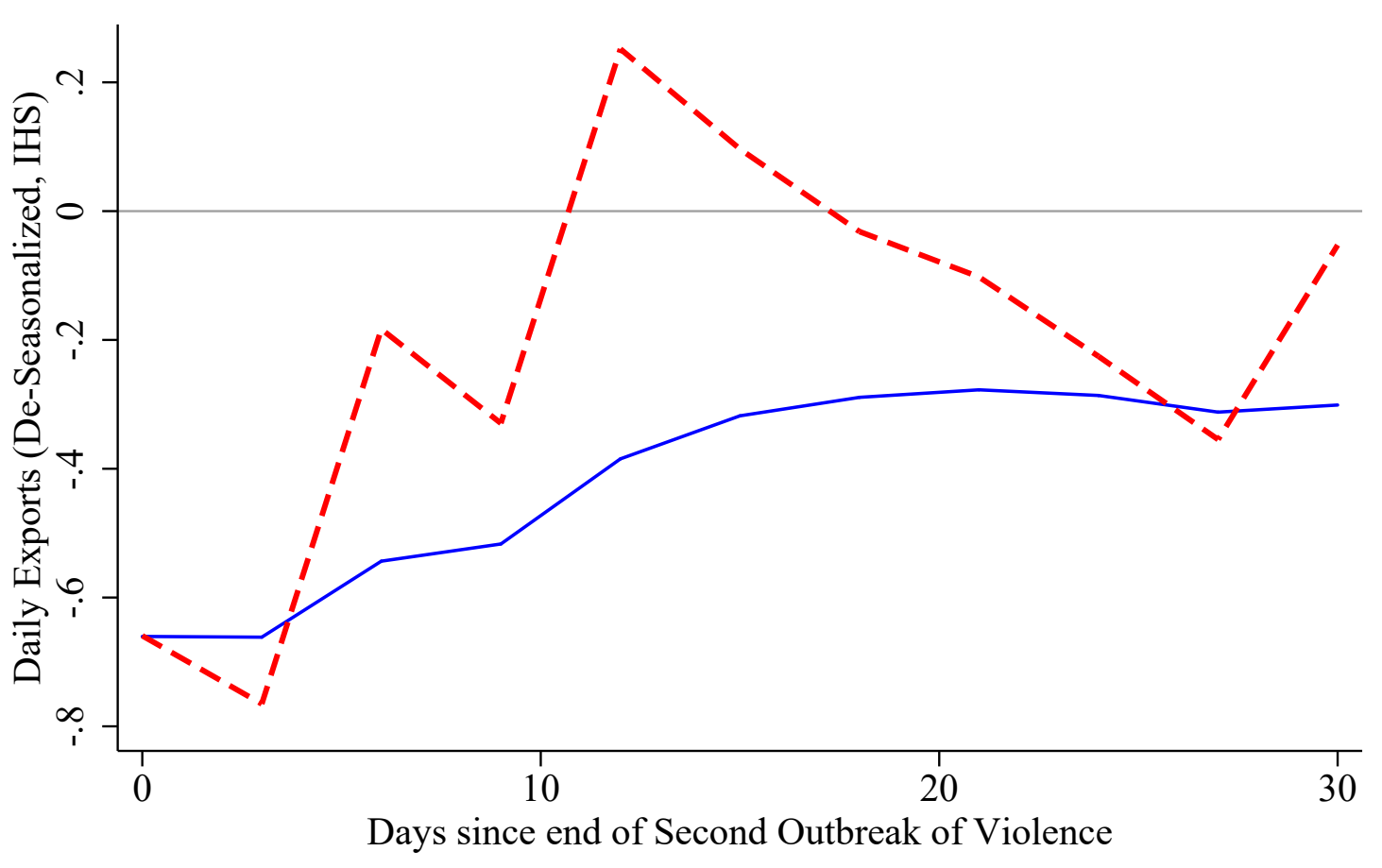

\section{Cumulative Estimate - - - - - Estimate}

Note: The figure displays the estimated coefficients of the differential cumulative and medium-run effects of the violence following the second outbreak of violence (from Jan. 30, 2008 on wards) on daily exports (kgs, inverse hyperbolic sine transformation) using the baseline specification in column (4) of Table 3. The estimate peaks around 14 days after the end of the second outbreak of violence reflecting firm's efforts to export for Valentine's Day. 


\section{Appendix Tables}

Table C1: Location of Firms and Definition of Violence

\begin{tabular}{cccc}
\hline \hline Panel A & & $\begin{array}{c}\text { First Outbreak } \\
\text { of Violence }\end{array}$ & $\begin{array}{c}\text { Second } \\
\text { Outbreak of } \\
\text { Violence }\end{array}$ \\
\hline Flower Cluster & No. firms & $\begin{array}{c}\text { Violence }=1, \\
\text { No-violence }=0\end{array}$ & $\begin{array}{c}\text { Violence }=1, \\
\text { No-violence }=0\end{array}$ \\
\hline Athi River & 10 & 0 & 0 \\
Kiambu & 18 & 0 & 1 \\
Mt Elgon & 6 & 1 & 0 \\
Mt Kenya & 13 & 0 & 0 \\
Nairobi & 5 & 0 & 0 \\
Naivasha & 38 & 0 & 1 \\
Nakuru & 20 & 1 & 0 \\
Thika & 25 & 0 & 1 \\
\hline & & & 0
\end{tabular}

Panel B

First Outbreak of Violence [29 Dec 2007 - 4 Jan 2008]

\begin{tabular}{cccc} 
Winter & No. Firms & Violence & No-violence \\
\hline 1 & 99 & 16 & 83 \\
2 & 111 & 17 & 94 \\
3 & 118 & 19 & 99 \\
4 & 135 & 20 & 115 \\
\hline \multicolumn{5}{r}{$\begin{array}{c}\text { Second Outbreak of Violence } \\
\text { Winter }\end{array}$} & No. Firms & Violence & 2008 & - 30 Jan 2008] \\
\hline 1 & 99 & 39 & No-violence \\
\hline 2 & 111 & 46 & 60 \\
3 & 118 & 47 & 65 \\
4 & 135 & 55 & 80 \\
\hline \hline
\end{tabular}

Note: This table provides details of the location of flower firms in violence and non-violence localities (Panel A). Flower clusters are designated by the industry body and are geographically dispersed across various provinces. The total number of firms is 135, by provinces they are located as follows: 53 firms in Central, 18 in Eastern, 5 in Nairobi, and 60 in Rift Valley. Winter $=$ 4 refers to the $2007 / 08$ period, Winter $=3$ refers to the $2006 / 07$ period, Winter $=2$ refers to the $2005 / 06$ period and Winter $=1$ refers to the $2004 / 05$ period. 


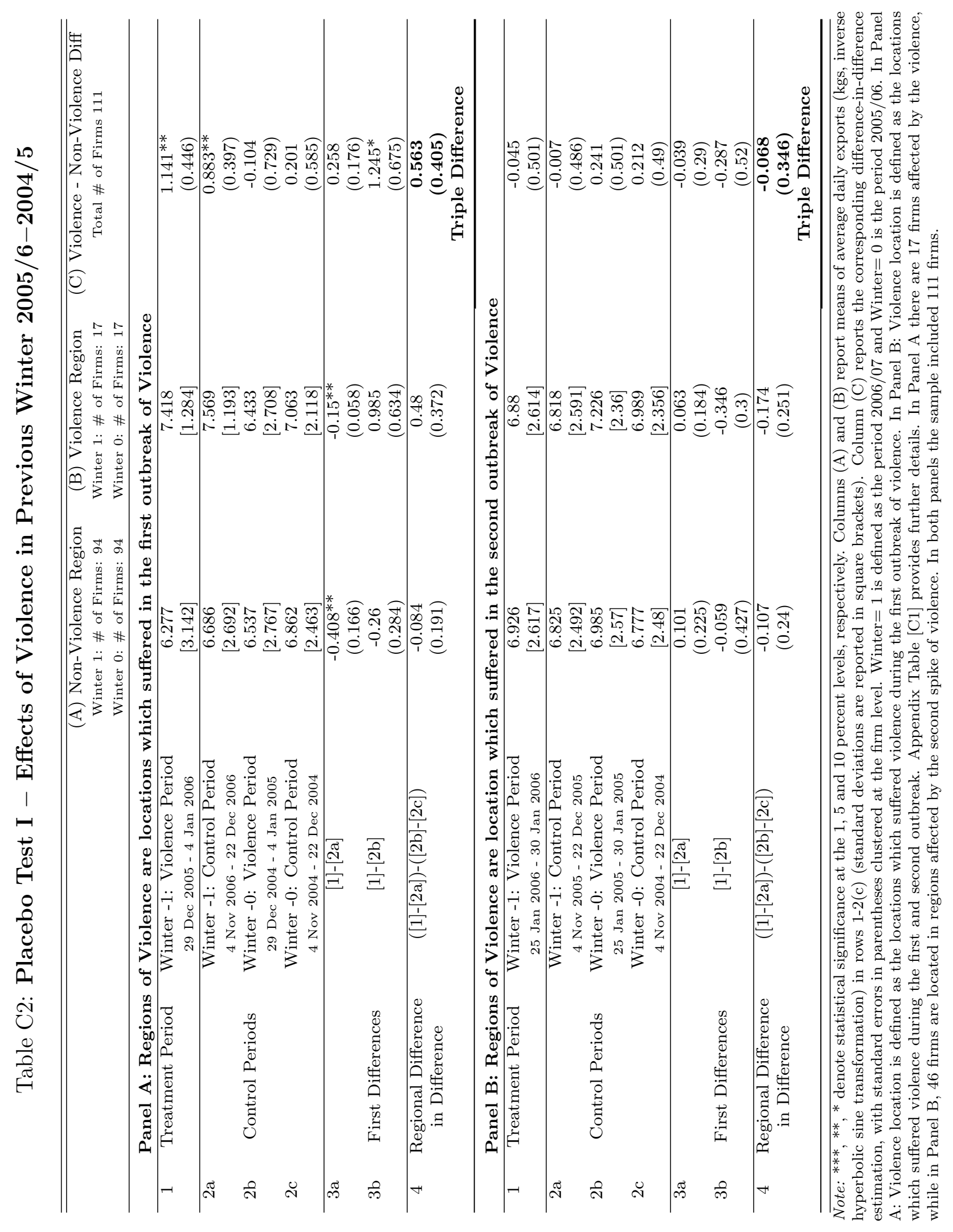




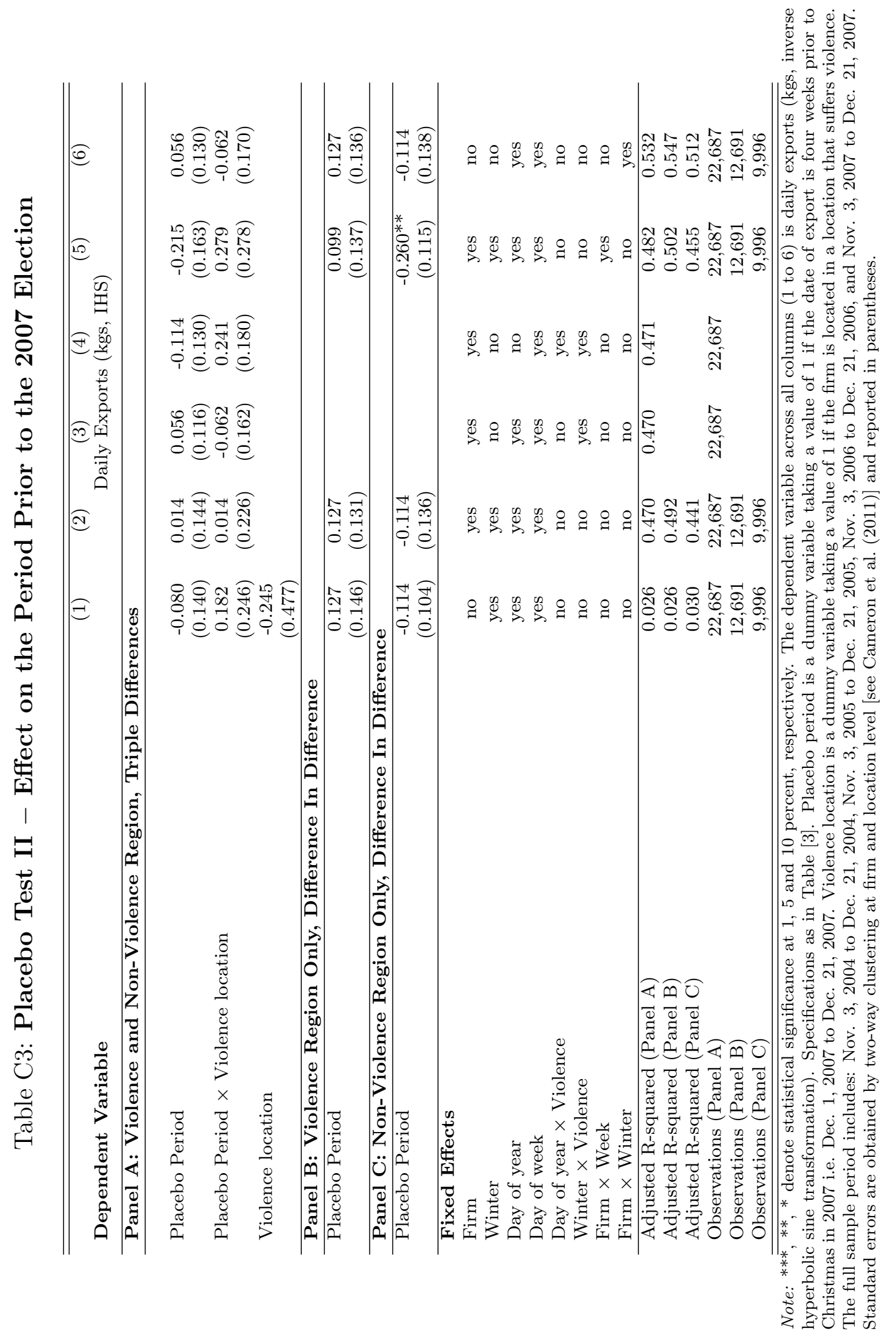




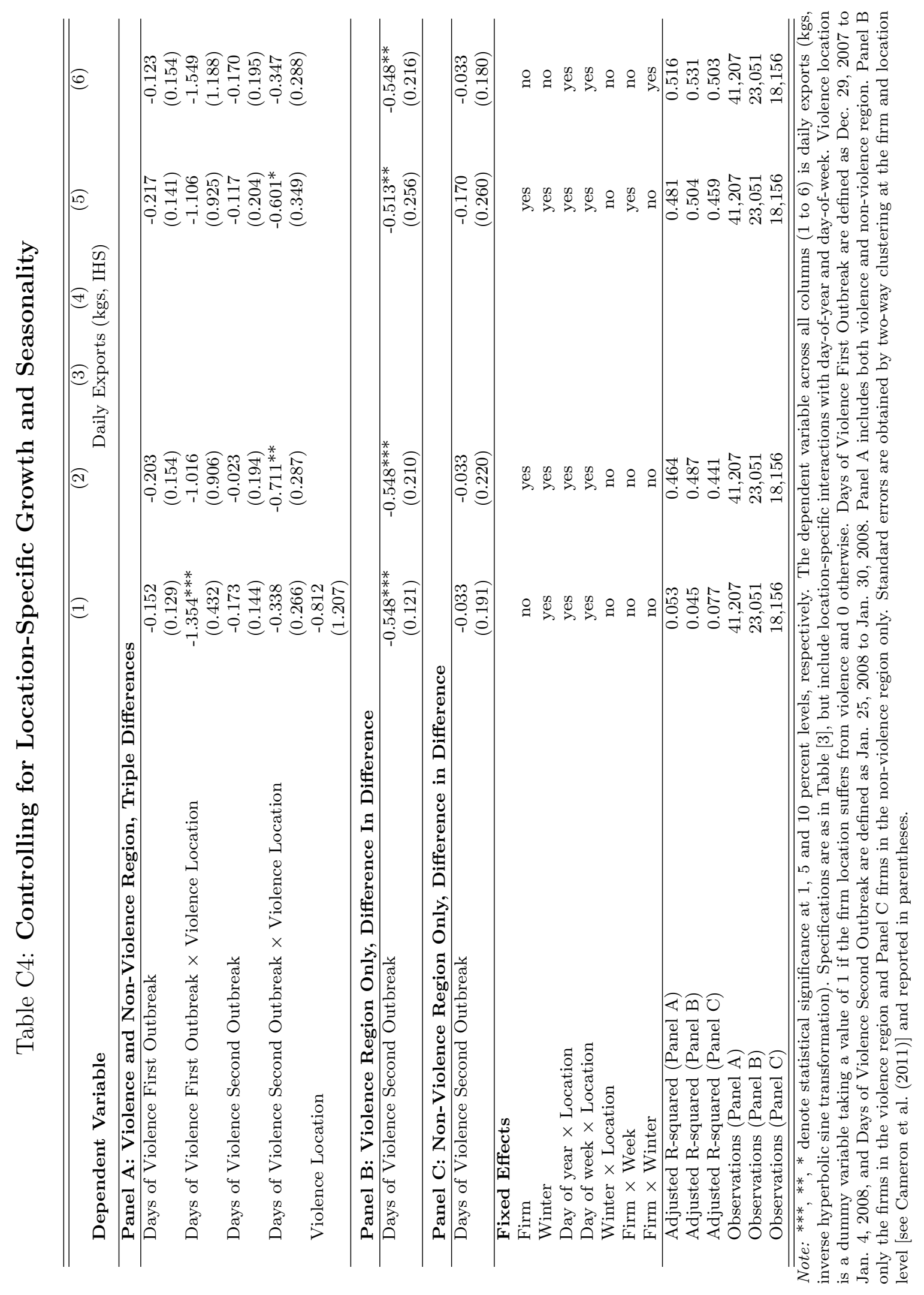




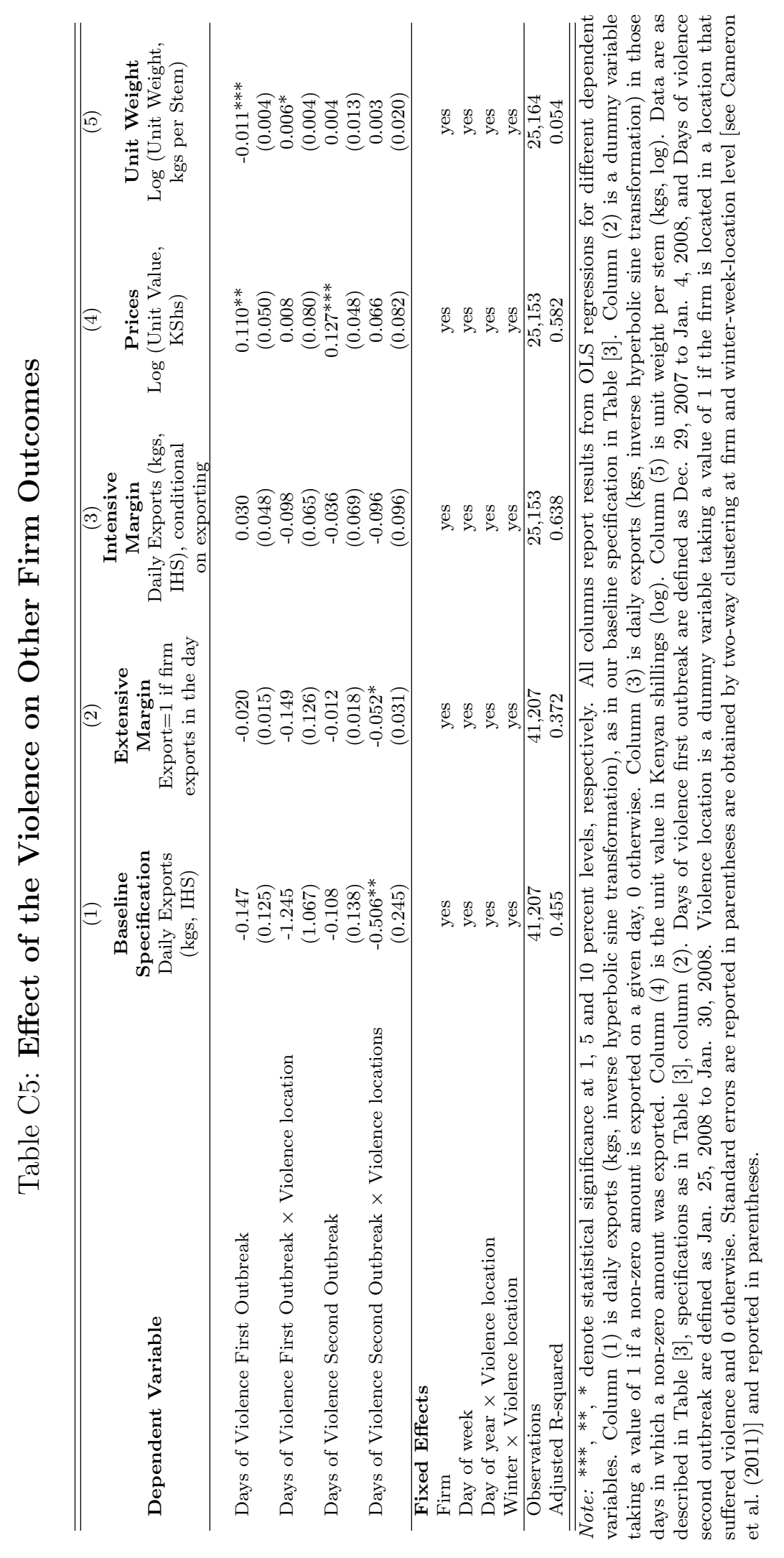




\section{Table C6: Worker and Transportation Problems}

\begin{tabular}{|c|c|c|c|c|c|}
\hline Dependent Variable & \multicolumn{5}{|c|}{ Daily Exports (kgs, IHS) } \\
\hline Week of Violence $\times$ Violence location & $\begin{array}{c}-0.637^{*} \\
(0.355)\end{array}$ & & & $\begin{array}{c}-0.296 \\
(0.327)\end{array}$ & \\
\hline $\begin{array}{l}\text { Workers Absent (\%) } \\
\text { Transportation Problems suffered by firm }\end{array}$ & & $\begin{array}{c}-1.103^{* *} \\
(0.541)\end{array}$ & $\begin{array}{c}-0.705^{* *} \\
(0.340)\end{array}$ & $\begin{array}{c}-0.456 \\
(0.514) \\
-0.418 \\
(0.321)\end{array}$ & $\begin{array}{c}-1.271^{* *} \\
(0.602)\end{array}$ \\
\hline \multicolumn{6}{|l|}{ Fixed Effects } \\
\hline Firm $\times$ Winter & yes & yes & yes & yes & yes \\
\hline Firm $\times$ Week & yes & yes & yes & yes & yes \\
\hline Observations & 24,030 & 24,030 & 24,030 & 24,030 & 12,638 \\
\hline R-squared & 0.445 & 0.445 & 0.445 & 0.445 & 0.474 \\
\hline
\end{tabular}

Note: $* * *, * \bar{*}, *$ denote statistical significance at 1, 5 and 10 percent levels, respectively. The dependent variable across all columns ( 1 to 5 ) is daily exports (kgs, inverse hyperbolic sine transformation). Sample period for the data set is four winters (2004 to 2008) over the period Nov. 3, 2004 to Jan. 30, 2008 for the 73 firms surveyed. Week of violence is a dummy variable taking a value of 1 if the date falls within the first (Dec. 29, 2007 to Jan. 4, 2008) or second outbreak of violence (Jan. 19, 2008 to Jan. 30, 2008. Workers Absent (\%) is the highest percentage of workers absent reported by the firm throughout the violence period, i.e., during the first six weeks of 2008. Violence location is a dummy variable taking a value of 1 if the firm is located in a location that suffers violence. Transportation Problems suffered by firm is a dummy variable taking a value of 1 if the firm responded of suffering transportation problems. Column (5) is a reduced sample as the analysis is only on firms that reported transportation problems (37 firms). Standard errors are obtained by two-way clustering at firm and winter-week-location level [see Cameron et al. (2011)] and reported in parentheses. 


\section{Data Appendix}

This appendix section provides information supplementary to Section 2 on the various data sources used in the paper.

\section{Transaction-level Export Data of Flower Firms in Kenya}

Transaction-level data on exports of flowers were obtained from the Kenya Horticultural Development Authority (HCDA) for the seasons 2004-2013. Each transaction invoice contains the following information: name of exporter, name of the foreign consignee/client, type of produce, weight (kgs), units, unit value, total value, date, destination, currency and the agreement on freight $(\mathrm{C} \& \mathrm{~F}, \mathrm{FOB})$.

\section{Transaction-level Export Data of Flower Firms for Ethiopia}

Transaction-level data on exports of flowers were obtained from the Ethiopian Horticultural Development Agency (EHDA) for the seasons 2007-2010. Each transaction invoice contains the following information: name of exporter, name of the foreign consignee/client, type of produce, weight (kgs), units, unit value, total value, date, destination, currency and the agreement on freight (C\&F, FOB). For additional details on the Ethiopian context and data see Antić and Morjaria (2020).

\section{Firm-level Survey}

A firm survey was designed by the authors which covered (i) general questions about the firm (history, farm certification, ownership structure, vertical integration, location of farms, etc.), (ii) contractual relationships in export markets and marketing channels (direct wholesaler and/or auction houses), (iii) firm production (covering detailed information on labor force, input use, and assets), (iv) operations during violence period (effect on operations, absence of workers by week, issues on transportation and air-freight, financial losses and extra-costs incurred). The survey was administrated and implemented by two of the authors between July and September 2008.

The sampling frame was constructed combining multiple sources of information: the list of exporters in the customs records, and the members of relevant firms' associations (Kenya Flower Council [KFC], Fresh Produce Exporters Association of Kenya [FPEAK], and Kenya Private Sector Alliance [KEPSA]. The membership lists of the flower associations included contact information for the firms, although the list from FPEAK had several

instances of contacts that were out-of-date and were generally of lower quality than the KFC list. Customs records do not include contact details for the firms. We thus complemented the 
search of contacts for firms through a variety of other sources, including internet searches, snowball interviews and our extensive time in the field.

We attempted to contact and survey all the firms for which we obtained contact details. The first contact was done by the authors over the phone. We would then set up an appointment for a face-to-face interview. Firms' responses to this type of contact request is often low. Initially, this was not different in our case. After initial setbacks, we were able to interview a firm whose owner was a very active member of KFC. The respondent took interest in the project and then facilitated access to other members of KFC, our presence on the ground further enabled access. Finally, for firms we still could not reach over the phone to set up appointments, we contacted firms directly through in-person visits at the premises of their flower farms. This last effort that was mostly targeted towards firms in the conflict location.

Overall, our response rates are high for this type of firm survey. We were able to interview 75 firms out of $122(61 \%)$ for which we had confirmed a location for the farm. ${ }^{46}$

\section{Administrative-level Data}

We established contacts with the HCDA, KFC and KEPSA to assist us in obtaining the location of all firms in the sample. Further, the names of the directors of the firms were obtained from the Registrar of Companies at the Attorney General's Office. These pieces of information allow us to classify the owner's nationality (Kenyan indigenous, Kenyan Indian or Foreign). For the firms which are under the ownership of Kenyan indigenous persons and Kenyan Indians, we map out whether the owners are politically connected or not. The data are assembled from the biographies of Member of Parliament's, further snowballing from interviews in the field, and various sources from the internet (e.g., The Kroll Investigative Report). Given the small number of firms, it is widely known in the industry which firms are politically connected. Information for each firm is cross-checked and triangulated using at least three different sources.

\section{Days of Violence and Conflict Location}

Locations are classified as having suffered conflict or not based on reports from Kenya Red Cross Society's (KRCS). The KRCS issued Information Bulletin on the Electoral Violence in

\footnotetext{
${ }^{46}$ In subsequent work in preparation for the 2013 election, as we attempted to identify locations of new firms via Google Maps and reports produced in the interim by the industry. We were also able to identify locations of firms (often smaller firms that were not part of the established grower associations) that we had not been able to find physical locations for in the 2008 data effort. These firms are part of the estimation sample we use to investigate exports Table 3 .
} 
the early stages of the crisis daily and later on every twice or so a week till the end of the crisis (see Kenya Red Cross Society (2008) for additional details). The first information bulletin (No. 1 of January 3, 2008) also contained a map which outlined locations where unrest had occurred. We further obtain access to various sources to supplement our understanding on both whether the location suffered conflict and when this took place. These are:

1. Disaster Desk of the Data Exchange Platform for the Horn of Africa (DEPHA): during the post-election violence DEPHA provided maps with hot spots on where and when the violence had occurred. DEPHA's mandate is to provide geographic information data and services to the region under the UN's OCHA. We obtained all the DEPHA maps from: http://www.depha.org, accessed on September 23, 2008.

2. Open source project Ushahidi was also launched to gather information from the general public on events occurring in near-real time. The public could pin on a online map of Kenya when and where conflict had erupted. Details on Ushahidi: http://www. ushahidi.com/about, and the Kenya project: http://legacy.ushahidi.com/ can be found on these links (accessed on September 30, 2008).

3. Kenya National Commission on Human Rights Report (2008).

4. Independent Review Commission Report (2008), initiated by the Government of Kenya to set up a commission into post-election violence.

These sources are useful additional sources of information to make sure we are exhaustive and that smaller towns are not missed out. We use these reports to aid our understanding but are aware that there could be an inherent measurement error due to their objective.

\section{Armed Conflict Location and Event Data Project (ACLED)}

We obtain data from ACLED for Kenya to supplement our measure of both location and days of violence. ${ }^{47}$ ACLED provide GPS coordinates for where violence occurred, and how many (if any) fatalities resulted from the violence. Based on these data, and the location of the flower firms (details below), we construct four measures of proximity and intensity of violence used in Table [4, for three concentric circles around the firms of radius $5 \mathrm{~km}, 10$ $\mathrm{km}$, and $20 \mathrm{~km}$ :

\footnotetext{
${ }^{47}$ ACLED Version 4 (1997-2013): http://www.acleddata.com/data/version-4-data-1997-2013/, accessed April 2014.
} 
1. Was there any episode of violence in the election time within a radius of $5 \mathrm{~km}, 10 \mathrm{~km}$, and $20 \mathrm{~km}$ around the firms' location?

2. Was there any episode of violence within a radius of $5 \mathrm{~km}, 10 \mathrm{~km}$, and $20 \mathrm{~km}$ around the firms' location?

3. Was there any episode of violence in which at least one fatality was recorded within a radius of $5 \mathrm{~km}, 10 \mathrm{~km}$, and $20 \mathrm{~km}$ around the firms' location?

4. What was the number of fatalities recorded within a radius of $5 \mathrm{~km}, 10 \mathrm{~km}$, and 20 $\mathrm{km}$ around the firms' location?

\section{Flower Farm Location}

In our initial firm survey in 2007 we were unable to include a GPS module; however, in 2014 we used two sources to help us identify the GPS coordinates of flower firms. The first source we used was Google satellite imagery to geo-tag flower firms. For flower farms that were not easily identifiable on Google Maps, we used a second source, maps of flower farm locations from industry reports. Maps from industry reports showed a selection of flower firms in growing clusters. These maps do not provide any coordinate system nor any scale. We try to geo-reference the maps by using other location information on the maps, such as certain main roads and natural features (e.g., mountains, lakes, rivers, and forests). In instances where we failed to accurately pinpoint the location, coordinates were then taken from a point that is relatively close to the main road and the farm's staging area.

\section{Kenya Ethnic Census}

We use the population census of 1989 (Government of Kenya, 1994) to obtain district ethnic demographics. The 1989 National Population Census was the last Kenyan census that publicly released sub-national ethnic population. The population census reports 41 ethnic

classifications. In line with studies on the politics of Kenya (e.g., Burgess et al. (2015) and Morjaria (2018)), we aggregate the ethnic classifications into 13 ethnic groups from just over 40 groups reported in the census. These 13 ethnic groups are Kikuyu, Kalenjin, Kamba, Luo, Luhya, Maasai, Coastal, Embu, Kisii, Meru, Somali, Turkana-Samburu, and Other (which are Other Africans, Arabs, Asians, Non-Africans).

\section{Elections and Electoral Violence}

Data on the frequency of elections and electoral violence were compiled from various country- 
specific Human Rights Reports published by the U.S. Department of State. Reported incidents of election-related violence were then categorized on the basis of timing - i.e., whether they occurred before, during, or after the election period and within the same calendar year. Violence "any time" reported in Figure 1 encompasses all three categories. The Human Rights Reports are prepared by State Department officials from information provided by a variety of sources including U.S. and foreign government officials, victims of alleged human rights abuses, academic and congressional publications, press reports, and reports from relevant international organizations and nongovernmental organizations. Reports are available for each year for each country for the years 1993 through 2018. Reports provide sufficient information about the most recent election preceding the year 1993, thus allowing us to assess the years 1990-1992, as well. Consequently, our data set, contains information on the number and type of elections and electoral violence for the years 1990-2018. To classify elections as non-violent or violent, we use the definition provided in Straus and Taylor (2009). We include violence before the elections (during campaigning, whether there were violent protests or harassment of political figures), during the elections (protests, harassment or other violence on election day), and after the elections (whether there was any disturbance after the results were announced). Elections can belong to one of four categories:

- No violence in connection with the election, coded as 0.

- Violent harassment: is defined by Straus and Taylor (2009) on page 10 as events "indicated by police breaking up rallies, party supporters fighting, street brawls, opposition newspapers being confiscated, and limited short-term arrests of political opponents", these type of elections are coded as 1 .

- Violent repression: is defined by Straus and Taylor (2009) on page 10 as events "indicated by long-term high-level arrests of party leaders, the consistent use of violent intimidation, limited use of murders and assassinations, and torture", these type of elections are coded as 2.

- Highly violent election: is defined by Straus and Taylor (2009) on page 11 as events that are "repeated, coordinated physical attacks leading to 20 or more deaths", these type of elections are coded as 3 .

We classify an election as violent if it is in category 1, 2, or 3 Straus and Taylor (2009) uses only categories 2 and 3 as violent). There is no objective line between categories $0-1-2$, each 
election has to be assessed based on the information given in the Human Rights Reports. We use our best judgement to classify the events. In some cases our assessment is different from that of Straus and Taylor (2009).

For each African country, we assess whether there was an election in the country, the type of the election (national, presidential, parliamentary, legislative, regional, local, byelection), and whether there was any electoral violence. We analyze national, presidential, parliamentary, or legislative elections only. We believe that these nationwide elections are of interest to the type of market instability our paper focuses on, also, the sub-national level elections might not be as thoroughly assessed in the Human Rights Reports, hence we are not confident that we have knowledge of all of these sub-national elections. Following Straus and Taylor (2009), presidential and parliamentary/legislative elections not held at the same time are counted as two elections for the same year if there was more than three months gap between them. If they were held within three months of each other, we count them as one election. Lastly, Human Rights Reports for 1999-2018 are available online: https://www. state.gov/j/drl/rls/hrrpt/ (accessed October 1, 2019). Older reports are available on archived websites, for example for 1998 see: https://1997-2001.state.gov/ global/human_rights/1998_hrp_report/98hrp_report_toc.html. 